\title{
Refreezing on the Greenland ice sheet: a comparison of parameterizations
}

\author{
C. H. Reijmer ${ }^{1}$, M. R. van den Broeke ${ }^{1}$, X. Fettweis ${ }^{2}$, J. Ettema ${ }^{1,{ }^{*}}$, and L. B. Stap \\ ${ }^{1}$ Institute for Marine and Atmospheric Research Utrecht, Utrecht University, Utrecht, \\ The Netherlands \\ ${ }^{2}$ Département de Géographie, Université de Liège, Liège, Belgium \\ *now at: Faculty of Geo-Information and Earth Observations, University of Twente, \\ Enschede, The Netherlands
}

Correspondence to: C. H. Reijmer (c.h.tijm-reijmer@uu.nl)

Received: 6 September 2011 - Published in The Cryosphere Discuss.: 18 October 2011

Revised: 1 June 2012 - Accepted: 4 June 2012 - Published: 11 July 2012

\begin{abstract}
Retention and refreezing of meltwater are acknowledged to be important processes for the mass budget of polar glaciers and ice sheets. Several parameterizations of these processes exist for use in energy and mass balance models. Due to a lack of direct observations, validation of these parameterizations is difficult. In this study we compare a set of 6 refreezing parameterizations against output of two Regional Climate Models (RCMs) coupled to an energy balance snow model, the Regional Atmospheric Climate Model (RACMO2) and the Modèle Atmosphérique Régional (MAR), applied to the Greenland ice sheet. In both RCMs, refreezing is explicitly calculated in a snow model that calculates vertical profiles of temperature, density and liquid water content. Between RACMO2 and MAR, the ice sheet-integrated amount of refreezing differs by only $4.9 \mathrm{~mm}$ w.e $\mathrm{yr}^{-1}(4.5 \%)$, and the temporal and spatial variability are very similar. For consistency, the parameterizations are forced with output (surface temperature, precipitation and melt) of the RCMs. For the ice sheet-integrated amount of refreezing and its inter-annual variations, all parameterizations give similar results, especially after some tuning. However, the spatial distributions differ significantly and the spatial correspondence between the RCMs is better than with any of the parameterizations. Results are especially sensitive to the choice of the depth of the thermally active layer, which determines the cold content of the snow in most parameterizations. These results are independent of which RCM is used to force the parameterizations.
\end{abstract}

\section{Introduction}

The surface mass balance (SMB) of a glacier is defined as the sum of all processes adding mass to the surface (accumulation) minus all processes removing mass (ablation):

$\mathrm{SMB}=\int_{1 \mathrm{yr}} d t\left(C+\mathrm{RF}-\mathrm{SU}_{\mathrm{s}}-\mathrm{SU}_{\mathrm{ds}}-\mathrm{ER}_{\mathrm{ds}}-\mathrm{RU}\right)$.

The most important contribution to accumulation is snowfall $(C)$, with additional contributions of condensation and freezing of rainfall (RF). Removal of mass occurs by means of surface sublimation $\left(\mathrm{SU}_{\mathrm{S}}\right)$, sublimation of drifting snow $\left(\mathrm{SU}_{\mathrm{ds}}\right)$, erosion by drifting snow $\left(\mathrm{ER}_{\mathrm{ds}}\right)$, and melt and subsequent runoff (RU). Especially in the (sub)polar regions, where glaciers are usually polythermal, part of the meltwater percolates into the snow/firn and refreezes. Refreezing has been addressed by several authors, especially in relation to the estimated contribution of glaciers to sea level rise (e.g. Trabant and Mayo, 1985; Pfeffer et al., 1990, 1991; Braithwaite et al., 1994; Schneider and Jansson, 2004; Reijmer and Hock, 2008; Fausto et al., 2009). Although its importance for the Greenland Ice Sheet (GrIS) is acknowledged, refreezing estimates are scarce and cover a wide range of values (Box et al., 2006; Fettweis, 2007; Hanna et al., 2008; Ettema et al., 2009).

The process of refreezing can be split in two main components: refreezing of meltwater percolating in the cold snow/firn in spring, and refreezing of liquid water held by capillary forces when the winter cold wave penetrates the 
firn. The former can be split into homogeneous and heterogenous infiltration of water and subsequent refreezing. In homogeneous infiltration water moves homogeneously from the surface through the snow and firn while in heterogeneous infiltration water infiltrates the firn along "pipes", transporting water to larger depths (Marsh and Woo, 1984; Pfeffer and Humphrey, 1996). Refreezing is an important process: it increases the temperature and density of the snow/firn and delays and reduces runoff, it reduces melt in the ablation zone since it delays bare ice exposure, and impacts mass balance profiles since it enhances mass accumulation around the equilibrium line and in the percolation zone above.

Most published work on refreezing describes homogeneous infiltration and subsequent refreezing, and refers to estimates for the GrIS, e.g. Pfeffer et al. (1991); Braithwaite et al. (1994); Fausto et al. (2009), although some estimates for individual glaciers in the Arctic are available (Trabant and Mayo, 1985; Schneider and Jansson, 2004; Reijmer and Hock, 2008; Wright et al., 2007). Bøggild (2007) and Wright et al. (2007) focussed on estimating superimposed ice formation, while Schneider and Jansson (2004) and Reijmer and Hock (2008) discussed the impact of refreezing on the glacier mass balance. A few observational studies on water infiltration are available as well (Marsh and Woo, 1984; Pfeffer and Humphrey, 1996; Humphrey et al., 2012). These observational studies show the importance of heterogeneous infiltration (piping) in the process of water infiltration and heating of cold firn. Given the wide range of applications and parameterizations, several authors attempted to compare the available parameterizations, most notably Janssens and Huybrechts (2000) and Wright et al. (2007). These comparisons are hampered by the scarcity of refreezing observations, although Wright et al. (2007) did compare their results with observed superimposed ice layers in ice cores.

Janssens and Huybrechts (2000) studied the spatial variability of refreezing in Greenland using different parameterizations forced by output of a degree day model, and a temperature and precipitation climatology. They report a strong dependency on the chosen depth of the thermally active layer, which in these expressions largely determines the cold content of the snow before the melting season starts. They conclude that to account for the effects of refreezing below this depth requires a more comprehensive calculation of the temperature profile in the upper ice and snow layers. Several authors have explicitly incorporated the refreezing process in their energy, mass balance or (regional) climate models (Bougamont et al., 2005; Fettweis et al., 2005; Reijmer and Hock, 2008; Ettema et al., 2010b). For many climate studies involving ice sheet evolution over centuries to millennia it is, however, still too computationally expensive to explicitly include this process, and parameterizations will remain necessary.

This study aims at improving our insight in the performance of various refreezing parameterizations building on the study by Janssens and Huybrechts (2000). In the ab- sence of observations, we use, as a reference, data of two regional climate models (RCMs) (Fettweis et al., 2005; Ettema et al., 2009) in which refreezing is explicitly calculated: the Regional Atmospheric Climate Model (RACMO2) and the Modèle Atmosphérique Régional (MAR). For consistency atmospheric data (temperature, precipitation, melt) from the RCMs are used to force the selected refreezing parameterizations. We then compare the results of the parameterizations to the amount of refreezing calculated by the models, using RACMO2 as reference. We furthermore discuss the impact and sensitivity of the values of the different input parameters to the parameterizations.

\section{Parameterizations}

The amount of refreezing is limited by (1) the available energy, (2) the available pore space in the snow/firn, and (3) the available amount of water from melt, condensation, and rain. Following Janssens and Huybrechts (2000), we define $P_{\mathrm{r}}$ as the potential retention mass, which is the maximum amount of water that can be refrozen, and is determined by (1) and (2). We define $W_{\mathrm{r}}$ as the available water mass (3) and $E_{\mathrm{r}}$ as the effective retention mass, which is the actual mass refrozen in the snow. $P_{\mathrm{r}}, W_{\mathrm{r}}$ and $E_{\mathrm{r}}$ are related by:

$E_{\mathrm{r}}=\min \left[P_{\mathrm{r}}, W_{\mathrm{r}}\right]$

By defining the retention mass as outlined above it equals the amount of refrozen mass. On an annual time scale, this estimate includes the meltwater that refreezes in the cold snow in spring, the meltwater that refreezes at depth to form superimposed ice and the capillary retained water that remains in the snow pack until the end of the melt season, and subsequently refreezes in winter. Note that the meltwater that refreezes in spring and superimposed ice may melt again and run off later in the melt season.

Below we describe several published parameterizations to calculate $P_{\mathrm{r}}$ and $E_{\mathrm{r}}$, and the modifications we made where necessary. These methods do not necessarily include all important processes or, for instance, include rain in the estimation of $W_{\mathrm{r}}$ and thus $E_{\mathrm{r}}$. Note that none of these parameterizations include the process of heterogeneous infiltration. Table 1 presents the selected parameterizations and their required input fields. The fields used to force the parameterizations are described in Sect. 3. All parameters referring to mass are in $\mathrm{mm}$ water equivalent (w.e.) unless stated otherwise.

\section{1 $P_{\max }$ formulations}

$P_{\max }$ formulations are the simplest way to calculate refreezing. They assume runoff to occur when the amount of refreezing exceeds a maximum fraction $\left(P_{\max }\right)$ of the annual snowfall $(C)$ :

$P_{\mathrm{r}}=P_{\max } \cdot C$, 
Table 1. The tested parameterizations. $W_{\mathrm{r}}$ refers to whether the available water mass in Eq. (2) equals melt $(M)$ or melt plus rain. Input $P_{\mathrm{r}}$ lists the input fields to $P_{\mathrm{r}}$, period refers to the period over which the input fields to $P_{\mathrm{r}}$ are averaged. The constants presented in the last column are chosen to correspond to the settings in the original publications. Note that RACMO2 fields are used as input and reference unless stated otherwise.

\begin{tabular}{llllll}
\hline & Abbr. & Input $W_{\mathrm{r}}$ & Input $P_{\mathrm{r}}$ & Period & Comments \\
\hline Ettema et al. (2010b) & RACMO2 & $M$ + Rain & - & - & SOMARS \\
Fettweis et al. (2005) & MAR & $M$ + Rain & - & - & CROCUS \\
Reeh (1991) & Re1991 & $M$ & $C$ & Annual & $P_{\mathrm{max}}=0.6$ \\
Pfeffer et al. (1991) & Pf1991 & $M$ & $C, M$ & Period & $\rho_{\mathrm{pc}}=900 \mathrm{~kg} \mathrm{~m}^{-3} \rho_{\mathrm{f}}=300 \mathrm{~kg} \mathrm{~m}^{-3} T_{\mathrm{f}}=-15^{\circ} \mathrm{C}$ \\
Janssens and Huybrechts (2000) & JH2000 & $M$ + Rain & $C, M, T_{\mathrm{S}}$ & Annual & $\rho_{\mathrm{pc}}=960 \mathrm{~kg} \mathrm{~m}^{-3} \rho_{\mathrm{f}}=300 \mathrm{~kg} \mathrm{~m}^{-3}$ \\
Huybrechts and de Wolde (1999) & HdW1999 & $M$ + Rain & $T_{\mathrm{S}}$ & Annual & $d_{\text {ice }}=2 \mathrm{~m}$ \\
Wright et al. (2007) & Wr2007 & $M$ + Rain & $T_{\mathrm{s}}, T_{\mathrm{W}}$ & Period & $d_{\text {ice }}=5 \mathrm{~m}$ \\
Oerlemans (1991) & Oe1991 & $M$ & $Q, T_{\mathrm{S}}$ & Time step & \\
\hline
\end{tabular}

where $P_{\mathrm{r}}$ is the potential retention mass. Reeh (1991) used $P_{\max }=0.6$, so that his modelled amount of melt from the GrIS agreed with other published estimates. Later research supports this value (Braithwaite et al., 1994). $P_{\max }$ may be varied from 0 , which is the lower bound with no refreezing possible, to 1 , which represents a case in which all water may be refrozen. The latter is only a meaningful solution at the higher parts of the ice sheet. In the remainder Re1991 refers to the $P_{\max }$ method.

\subsection{Physically based formulations}

A more physically based approach was proposed by Pfeffer et al. (1991) (henceforth Pf1991). Pf1991 defines a runoff elevation $h_{\mathrm{r}}$ above which all melt water refreezes, while below this elevation all melt water runs off. This runoff elevation is determined by a combination of two requirements. The first is that for part of the melt water to run off, the amount must be large enough to remove the cold content of the snow, thus enough water must first refreeze in order to raise the snow temperature to $0^{\circ} \mathrm{C}$. The second requirement is that the melt water has to saturate the snow pore space up to the maximum value. This leads to the following condition for which runoff occurs:

$M \geq \frac{c_{\mathrm{i}}}{L_{\mathrm{f}}} C\left|T_{\mathrm{f}}\right|+(C-M)\left(\frac{\rho_{\mathrm{pc}}-\rho_{\mathrm{f}}}{\rho_{\mathrm{f}}}\right)$.

Here, $c_{i}$ is the heat capacity of ice that is usually assumed constant $\left(2050 \mathrm{~J} \mathrm{~kg}^{-1} \mathrm{~K}^{-1}\right)$, but sometimes as a function of air temperature $T_{\mathrm{a}}$ (in K): $c_{\mathrm{i}}=152.2+7.122 \cdot T_{\mathrm{a}}$ (Paterson, 1994). $L_{\mathrm{f}}$ is the latent heat of fusion for ice $\left(0.334 \times 10^{6} \mathrm{~J} \mathrm{~kg}^{-1}\right), T_{\mathrm{f}}$ is the initial firn temperature in ${ }^{\circ} \mathrm{C}$ at the runoff elevation, $\rho_{\mathrm{pc}}$ and $\rho_{\mathrm{f}}$ are the density at pore closeoff and the initial firn density, respectively (in $\mathrm{kg} \mathrm{m}^{-3}$ ). $C$ and $M$ are the mean annual amount of snowfall and melt, respectively (in $\mathrm{m}$ w.e.). The first term on the right hand side (r.h.s.) represents the removal of cold content where $C$, the annual mean snowfall, represents a variable thickness of the thermally active layer. The second term describes the saturation of the pore space in the remaining annual snowfall $(C-M)$, i.e. the refreezing of capillary water at the end of the melt season.

Pf1991 applied this method to the GrIS where they estimated $C$ and $M$ from synthesized melt and accumulation profiles. These profiles provided $h_{\mathrm{r}}=1680 \mathrm{~m}$, the elevation where the transition from refreezing to runoff occurs and $T_{\mathrm{f}}$ is then the characteristic temperature at $h_{\mathrm{r}}$. When applied to gridded data, with $\rho_{\mathrm{pc}}, \rho_{\mathrm{f}}$ and $T_{\mathrm{f}}$ taken constant in space and time (Table 1, values taken from Pf1991), the above condition provides us with a mask defining the area where refreezing occurs and the area where runoff occurs.

Janssens and Huybrechts (2000) (henceforth JH2000) modified the condition in Eq. (4) such that it provided $P_{\mathrm{r}}$ instead of a mask:

$P_{\mathrm{r}}=\frac{c_{\mathrm{i}}}{L_{\mathrm{f}}} C\left|T_{\mathrm{s}}\right|+(C-M)\left(\frac{\rho_{\mathrm{pc}}-\rho_{\mathrm{f}}}{\rho_{\mathrm{f}}}\right)$.

Here, $T_{\mathrm{s}}$ is the annual mean surface temperature (in ${ }^{\circ} \mathrm{C}$ ). To calculate the actual amount of refreezing on the GrIS, JH2000 additionally limited $E_{\mathrm{r}}$ to the total annual precipitation $\left(P_{\mathrm{tot}}\right): E_{\mathrm{r}}=\min \left[P_{\mathrm{r}}, W_{\mathrm{r}}\right] \leq P_{\text {tot }}$. The forcing in JH2000 came from a degree day model providing $M$, an annual temperature climatology depending on latitude, surface elevation and time of year providing $T_{\mathrm{s}}$, and a total precipitation $\left(P_{\text {tot }}\right)$ climatology based on a.o. ice core measurements. The input fields we use are described in Sect. 3. $\rho_{p c}$ and $\rho_{f}$ are taken constant in space and time (Table 1, values taken from JH2000). With small variations, Eq. (5) has been applied to e.g. the GrIS by Fausto et al. (2009) and a small glacier on Svalbard by Wright et al. (2007).

Huybrechts and de Wolde (1999) (henceforth HdW1999) and Wright et al. (2007) (henceforth Wr2007) presented parameterizations based on the same principles as Pf1991 and JH2000 but neglected the refreezing due to capillary water (2nd term r.h.s. Eq. 5). The HdW1999 condition for refreezing is given by:

$P_{\mathrm{r}}=\frac{c_{\mathrm{i}}}{L_{\mathrm{f}}} d_{\mathrm{ice}}\left|T_{\mathrm{s}}\right|$, 
where $d_{\text {ice }}$ is the thickness of the thermally active layer. HdW1999 used a value of $d_{\text {ice }}=2 \mathrm{~m}$ w.e. based on observations at the equilibrium line in central west Greenland (Oerlemans, 1991).

In Wr2007 the energy available for refreezing, represented by $T_{\mathrm{s}}$ in the above equations, is expressed in $T_{\mathrm{s}}$ and $T_{\mathrm{w}}$, the period averaged annual and winter surface temperature. The expression was based on the integration between standard profiles of winter and summer snow temperature (based on observations at the end of winter and summer) assuming the area between these curves to be representative for the available energy:

$P_{\mathrm{r}}=\frac{c_{\mathrm{i}}}{L_{\mathrm{f}}} d_{\text {ice }} 0.5\left(\left(1-\frac{\pi}{2}\right) T_{\mathrm{s}}-T_{\mathrm{w}}\right)$.

Here, $d_{\text {ice }}$ is the maximum depth to which the annual temperature cycle penetrates, similar to the thermally active layer in Eq. (6). Wr2007 used Eq. (7) to estimate the amount of superimposed ice on a glacier on Svalbard. They obtained the best agreement with observations for $d_{\text {ice }}=5 \mathrm{~m}$ w.e.

\subsection{Energy balance formulation}

In the energy balance approach the amount of refreezing is linked to the sum of available energy at the surface. Oerlemans (1991) (henceforth Oe1991) applied the method in an energy balance model for the GrIS. In this method the available energy at the surface is the sum of all energy fluxes $(Q)$ :

$Q=\mathrm{Sw}_{\text {net }}+\mathrm{Lw}_{\text {net }}+\mathrm{SHF}+\mathrm{LHF}$,

where $\mathrm{Sw}_{\text {net }}$ is the net short wave radiation, $\mathrm{Lw}_{\text {net }}$ is the net long wave radiation, and SHF and LHF are the turbulent fluxes of sensible and latent heat, respectively. All fluxes are in $\mathrm{W} \mathrm{m}^{-2}$. The partitioning of the energy per time step that can be used for refreezing $\left(Q_{\text {ice }}\right)$ is determined by the average snow temperature $T_{\mathrm{sn}}$ (in ${ }^{\circ} \mathrm{C}$ ) of the upper $2 \mathrm{~m}$ of snow/firn:

$Q_{\text {ice }}=\max [Q, 0].\left(1-\exp \left(T_{\mathrm{sn}}\right)\right)$.

Thus, when temperature decreases, a larger fraction of the energy used for melt can be re-used for heating the snow through refreezing. Oe1991 initialized the model with the annual mean surface temperature. The energy released when refreezing occurs is used to increase the snow temperature. Oe1991 calculated this process each model time step of $15 \mathrm{~min}$. Using this relation we define $P_{\mathrm{r}}$ as:

$P_{\mathrm{r}}=\sum_{i=1}^{12} n_{i}\left(\frac{Q_{\mathrm{ice}}(i)}{L_{\mathrm{f}}}\right)$

where the sum is taken over 12 months since our input consists of monthly mean values, and $n_{i}$ is the number of $15 \mathrm{~min}$ time steps in each month. Oe1991 only applied this formulation over snow surfaces since refreezing can only occur in snow or firn. We therefore limit $P_{\mathrm{r}}$ to the total annual precipitation $P_{\text {tot }}$ similar to JH2000: $E_{\mathrm{r}}=\min \left[P_{\mathrm{r}}, W_{\mathrm{r}}\right] \leq P_{\text {tot }}$. We furthermore use $T_{\mathrm{s}}$ to represent $T_{\mathrm{sn}}$. Note that we do not take the heating effect of refreezing on $T_{\mathrm{sn}}$ into account.

\section{Regional Climate Models}

The above parameterizations will be forced by and compared to output of two regional climate models: RACMO2 (Regional Atmospheric Climate MOdel, Van Meijgaard et al. 2008) and MAR (Modèle Atmosphérique Régional, Gallée and Schayes, 1994). Both models have been successful in simulating the mass budgets of the Antarctic ice sheet and/or the GrIS (see e.g. Gallée and Schayes, 1994; Fettweis, 2007; Fettweis et al., 2011; Van de Berg et al., 2006; Ettema et al., 2009; Lenaerts et al., 2012). For application over the GrIS, MAR uses a domain that includes part of Eastern Canada, Greenland, and part of Iceland, on a horizontal resolution of $25 \mathrm{~km}$. RACMO2 uses a horizontal resolution of $11 \mathrm{~km}$ and its domain additionally includes Iceland and Svalbard. In this study MAR is resampled to the RACMO2 domain and resolution. RACMO2 is forced at the lateral boundaries and at the sea surface by output of ERA40 (European Centre for Medium-Range Weather Forecasts (ECMWF) 40-yr re-analysis project) over 1958-2002, supplemented by ECMWF operational analyses over 20022008, while MAR uses ERA-40 over 1958-1999 and afterwards ERA-INTERIM (ECMWF interim re-analysis project) over 2000-2008. RACMO2 and MAR are two-way coupled to a physical energy balance snow model. RACMO2 is coupled to SOMARS (Simulation Of glacier surface Mass balance And Related Sub-surface processes, Greuell and Konzelman, 1994) and MAR to CROCUS (Brun et al., 1992). We refer to Ettema et al. (2010b) for a more detailed description of RACMO2 and to Gallée and Schayes (1994); Fettweis (2007) for a more detailed description and set-up of MAR. Both snow models are described below. Results of the application of RACMO2 and MAR to the GrIS are published in e.g. Lefebre et al. (2005); Fettweis (2007); Ettema et al. (2009, 2010a,b); Van den Broeke et al. (2009); Fettweis et al. (2011).

\subsection{The coupled snow models}

\subsubsection{SOMARS}

The snow model incorporated in RACMO2 (SOMARS) follows Greuell and Konzelman (1994); Bougamont et al. (2005); Reijmer and Hock (2008) to calculate the process of meltwater percolation, retention, and refreezing as well as the formation and merging of deep snow layers. The snow model is applied interactively to each horizontal glacier grid point. It uses a vertical grid that consists of layers with variable 
thickness, ranging from $\sim 6.5 \mathrm{~cm}$ near the surface to $\sim 4 \mathrm{~m}$ at $30 \mathrm{~m}$ depth. The thickness of the layers is allowed to change in each model time step (6-10 minutes) due to melt, accumulation, evaporation, and densification. Each layer is characterized by a temperature, density, liquid water content, depth and thickness. No mass exchange is allowed between horizontal grid points.

The snow model is interactively coupled to the atmospheric part of RACMO2 through the surface albedo and the surface skin temperature $T_{\mathrm{s}}$. The surface albedo is a function of snow density and cloudiness following Greuell and Konzelman (1994). The skin temperature $T_{\mathrm{s}}$ is the temperature of an infinitely thin layer (i.e. without heat capacity). $T_{\mathrm{S}}$ obeys the surface energy budget and reacts instantaneously to changes therein. $T_{\mathrm{S}}$ is calculated iteratively by closing the surface energy balance and then serves as boundary condition for the englacial model. Furthermore, $T_{\mathrm{S}}$ is limited to $273.16 \mathrm{~K}$; any excess heat is used for melting.

The temperature evolution of a snow layer $\left(\partial T_{\mathrm{sn}} / \partial t\right)$ is calculated based on the thermodynamic equation (Paterson, 1994):

$\rho c_{\mathrm{i}} \frac{\partial T_{\mathrm{sn}}}{\partial t}=\frac{\partial}{\partial z}\left(K \frac{\partial T_{\mathrm{sn}}}{\partial z}\right)+L_{\mathrm{f}} F$,

where $c_{\mathrm{i}}$ is the heat capacity of ice, $\rho$ is the (variable) density of a snow/firn/ice layer, $\partial T_{\mathrm{sn}} / \partial t$ is the rate of temperature change within a model time step, $K$ the effective conductivity, $z$ the vertical coordinate and $L_{\mathrm{f}} F$ the heat released by refreezing of water. Vertical heat conduction is not explicitly included because the layers are followed downwards when they are buried. $K$ is a function of snow properties and is described as a function of density $\rho$, neglecting its temperature dependency (Van Dusen, 1929):

$K=2.1 \times 10^{-2}-4.2 \times 10^{-4} \rho+2.2 \times 10^{-9} \rho^{3}$.

Melt and rain water are allowed to percolate into lower layers where it may refreeze, raising the temperature and density. Refreezing is limited by three factors: (1) the firn/snow temperature cannot be raised above the melting point, (2) the available amount of water (melt plus rain), and (3) the available pore space. The maximum amount of water retained against gravity (irreducible water content) is set to $2 \%$ of the pore volume. In the laboratory, values have been observed as high as $10 \%$ (Coléou and Lesaffre, 1998); by taking a lower value we assume a more effective transport of water towards lower layers accounting for processes such as piping. Water may percolate through the successive vertical layers until it reaches impermeable ice. No slush layer is allowed to form, the remaining liquid water runs off without delay.

The densification of dry snow is described by an empirical relation developed by Herron and Langway (1980) and depends on snow temperature $T_{\mathrm{sn}}$ and accumulation rate $a$ (in mw.e.).

$$
\begin{aligned}
& \frac{d \rho}{d t}=11 \exp \left(-\frac{10160}{R T_{\mathrm{sn}}}\right) a\left(\rho_{\mathrm{i}}-\rho\right) \\
& \text { for } \rho<550 \mathrm{~kg} \mathrm{~m}^{-3} \\
& \frac{d \rho}{d t}=575 \exp \left(-\frac{21400}{R T_{\mathrm{sn}}}\right) a^{0.5}\left(\rho_{\mathrm{i}}-\rho\right) \\
& \text { for } 550 \mathrm{~kg} \mathrm{~m}^{-3} \leq \rho<800 \mathrm{~kg} \mathrm{~m}^{-3}
\end{aligned}
$$

Here $\rho_{\mathrm{i}}$ is the ice density and $R$ the universal gas constant. The accumulation rate $a$ is based on a 16-year initialization run with RACMO2 and is variable in space but constant in time. This initialization run also provides the initial snow pack temperature, density and water content profiles.

\subsubsection{CROCUS}

The snow model incorporated in MAR (CROCUS) follows Gallée and Duynkerke (1997); Gallée et al. (2001); Lefebre et al. (2003). CROCUS uses a vertical grid that consists of layers with variable thickness, ranging from $<1 \mathrm{~cm}$ near the surface to $>1 \mathrm{~m}$ at $10 \mathrm{~m}$ depth. The thickness of the layers is allowed to change in each model time step (2 minutes). In addition to temperature, density, liquid water content, depth and thickness, each layer is characterized by snow grain parameters: dendricity, sphericity and descriptive grain size.

The snow model is interactively coupled to the atmospheric part of MAR through the surface albedo and the surface temperature $T_{\mathrm{s}}$. The surface albedo is a function of the simulated snow grain form and size (Brun et al., 1992), the snow depth above bare ice, the zenith angle and the cloudiness (Lefebre et al., 2003). $T_{\mathrm{S}}$ equals $T_{\mathrm{s}}$ of the upper layer and serves as input to the surface energy budget. $T_{\mathrm{S}}$ is limited to $273.16 \mathrm{~K}$; any excess heat is used for melting. The surface energy budget $Q$ is then used as input to the snow model through the thermodynamic equation:

$\rho c_{\mathrm{i}} \frac{\partial T_{\mathrm{sn}}}{\partial t}=\frac{\partial}{\partial z}\left(K \frac{\partial T_{\mathrm{sn}}}{\partial z}\right)+L_{\mathrm{f}} F+L_{\mathrm{f}} M+\frac{\partial Q}{\partial z}$,

where $L_{\mathrm{f}} M$ is the heat flux related to melt. In the uppermost layer $Q$ includes the net short and long wave radiation, and the surface turbulent heat fluxes. In the lower layers $Q$ only describes the penetration of short wave radiation. The effective conductivity $K$ is described as a function of density $\rho$ using the formulation of Yen (1981):

$K=2.22\left(\frac{\rho}{\rho_{\mathrm{w}}}\right)^{1.88}$,

where $\rho_{\mathrm{w}}$ is the density of liquid water.

The time evolution of the liquid water content of a layer follows the following relation:

$\rho \frac{\partial W_{\mathrm{r}}}{\partial t}=\frac{\partial}{\partial z}\left(-U_{\mathrm{W}}\right)+F+M$. 
The vertical water flux $U_{\mathrm{W}}$ is a function of density and snow grain size. The irreducible water content is set to $6 \%$ of the pore volume (Fettweis et al., 2011). Water may percolate through the successive vertical layers until it reaches impermeable ice. A slush layer is allowed to form (above bare ice) and the resulting delay in runoff is described by the parameterization of Zuo and Oerlemans (1996):

$t_{\text {runoff }}=c_{1}+c_{2} \exp \left(-c_{3} \tan (\beta),\right)$

where $t_{\text {runoff }}$ is the runoff time scale, which depends on the surface slope $\beta$, and coefficients $c_{1}, c_{2}$ and $c_{3}$, which are set to $0.33,25$ and 140 days, respectively.

The densification of dry snow is described by the following settling law (Brun et al., 1989):

$$
\begin{aligned}
& \frac{d D}{D}=\frac{-\sigma}{\eta} d t \\
& \text { with } \eta=\frac{6 \times 10^{4}}{1-f(s n)} \exp \left(0.023 \rho-0.1\left(T_{\mathrm{sn}}-273.16\right)\right) .
\end{aligned}
$$

Here $D$ is the layer thickness and $\sigma$ the vertical stress described by the weight of the overlying layers. $\eta$ is the snow viscosity, which is a function of the snow temperature $T_{\mathrm{sn}}$, density $\rho$, and snow type through $f(s n)$. The initial snow pack characteristics (temperature, density, water content and snow grain characteristics) are prescribed at the start, on the 1st of September 1957 and are based on the average snowpack behaviour occurring on the 1st of September from previous simulations.

\subsection{Modelled refreezing}

The fields and temporal variations of the annual ice sheet averaged amount of refrozen mass $\left(E_{\mathrm{r}}\right)$ calculated by RACMO2 and MAR are presented in Figs. 1 and 2. They show that refreezing in RACMO2 and MAR agree reasonably well although regionally differences occur. A detailed discussion of both fields with respect to the parameterizations is given in Sect. 4. Figure 1 shows that most refreezing occurs along the margins, where most melt occurs (Fig. 3b). In the widest ablation area (western ice margin) the amount of refrozen mass is limited by the rapid removal of the winter accumulated snow pack above bare ice at the beginning of summer, making pore space the limiting factor for refreezing. Most refreezing occurs on the wet south and south-eastern margins, where pore volume is much larger. The amount of refreezing just below the equilibrium line is considerable, see e.g. the local maximum on the western ice margin, and is related to multiple cycles of melt and refreezing.

Due to the lack of refreezing observations, the modelled refreezing cannot directly be robustly validated. An indication of how well the models perform with respect to refreezing is given by validation of the snow characteristics for single locations with in situ observations, and for the spatial distribution, by validation of the surface mass balance field and its components to satellite observations. For single locations Crocus and SOMARS are compared to observations by Greuell and Konzelman (1994); Lefebre et al. (2003); Reijmer and Hock (2008). Greuell and Konzelman (1994); Reijmer and Hock (2008) validate modeled snow temperatures and show that SOMARS is capable of modeling vertical profiles and temporal variations in snow temperature (Figs. 8 and 9 of Greuell and Konzelman, 1994, Fig. 5 of Reijmer and Hock, 2008). Fig. 5 of Reijmer and Hock (2008) also shows that incorporating refreezing is necessary to obtain the correct temporal variability in snow temperature. Lefebre et al. (2003) show that Crocus is capable of modeling water content and snow density at the Swiss ETH camp in western Greenland (their Figs. 8 and 9). Ettema et al. (2009) show a good comparison of the RACMO2 SMB with in situ observations (correlation coefficient $\mathrm{R}=0.95$, their Fig. S2). They also show good correlation with observations for the components of precipitation $(\mathrm{R}=0.9)$ and melt, with modeled average ablation along a transect on the western ice margin of $1417 \mathrm{~mm}$ w.e. $\mathrm{yr}^{-1}$ versus observed $1413 \mathrm{~mm}$ w.e. $\mathrm{yr}^{-1}$. Fettweis et al. $(2005,2011)$ evaluate MAR SMB by comparing modeled and observed (derived from satellite brightness temperature data and in situ observations) melt extent and number of melt days. In Fettweis et al. (2011) RACMO2 is included in the comparison. Although some biases are present, which are partly ascribed to satellite data processing issues and partly to model specific issues, RACMO2 and MAR show good spatial and temporal agreement with the satellite observed melt extent. Spatial agreement varies between $\mathrm{R}=0.88$ and 0.95 depending on satellite retrieval algoritm, and the number of melt days corresponds $97 \%$ of the cases with in situ observations. Furthermore, Van den Broeke et al. (2009) and Rignot et al. (2011) show good agreement between the ice sheet averaged RACMO2 and GRACE (Gravity Recovery and Climate Experiment satellites) derived monthly mass balance variability $(\mathrm{R}=0.99$, Fig. 1 in Van den Broeke et al., 2009). The capability of both models to reproduce the subsurface fields of temperature, density and water content in combination with the good spatial correspondence of the SMB and melt extent with observations provides confidence in the modeled refreezing.

\subsection{Input data}

We force the various parameterizations with the following input fields from RACMO2 and MAR: monthly snowfall, melt, rain, and, depending on the parameterization, surface temperature and net surface energy budget. Annual values of $P_{\mathrm{r}}$ are then calculated and Eq. (2) applied to annual values of $W_{\mathrm{r}}$ to provide annual values of $E_{\mathrm{r}}$. The parameterizations will be evaluated against RACMO2 fields unless stated otherwise. Note that the annual values are based on January to December monthly means or sums.

Figure 3 presents 1958-2008 average annual sums of snowfall (a), melt (b) and rain (c) for RACMO2. The most 


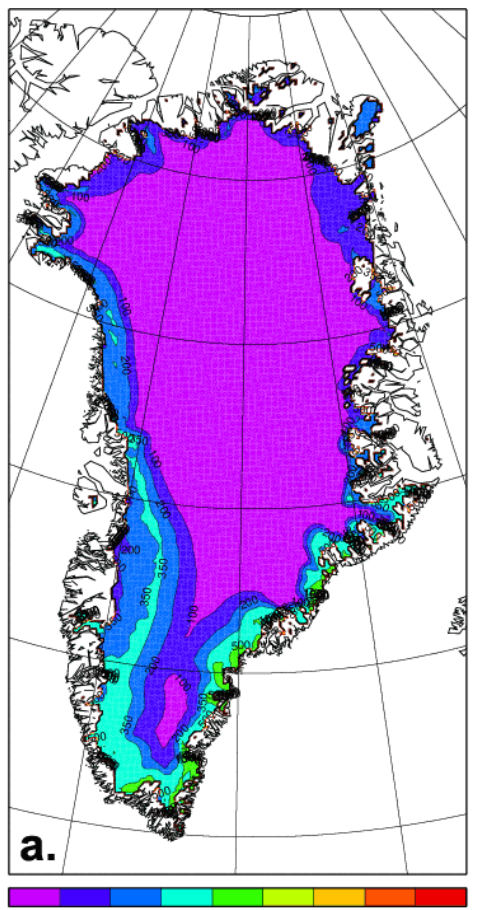

$0 \quad 100 \quad 200 \quad 350 \quad 500 \quad 75010001500250050000$
mm w.e. $\mathrm{yr}^{-1}$
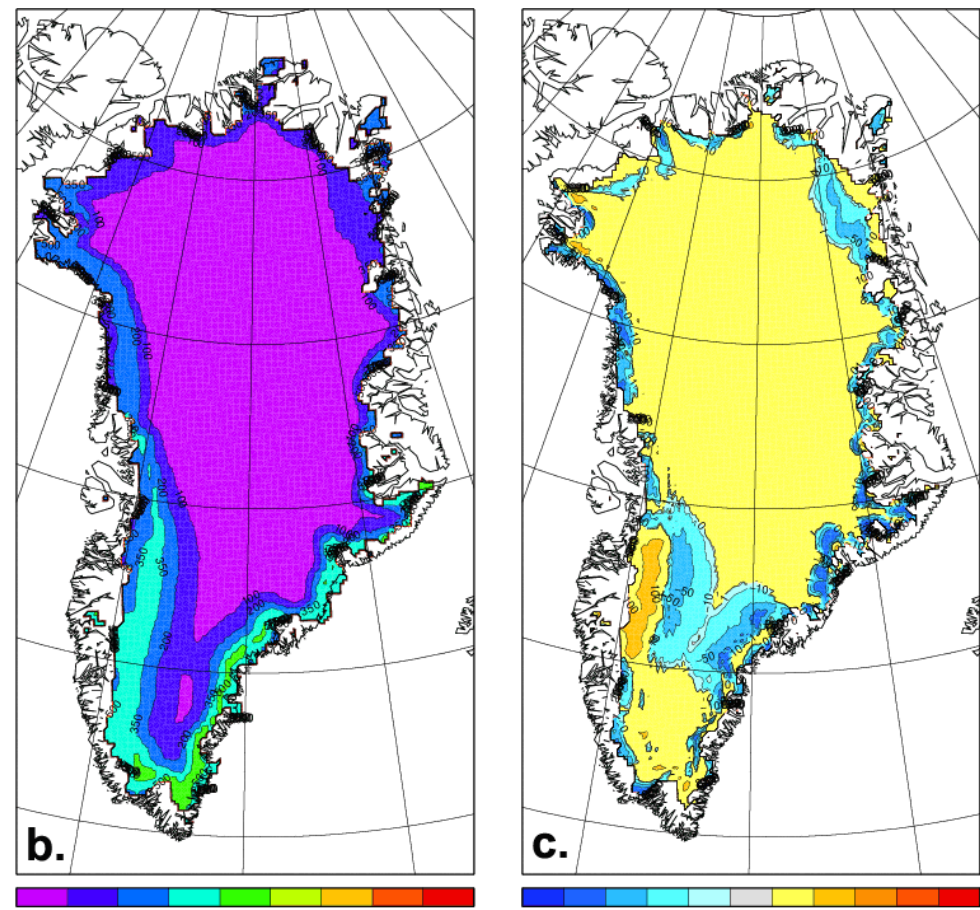

C.

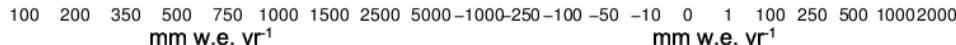

Fig. 1. Period (1958-2008) averaged anual sums of refrozen mass $\left(E_{\mathrm{r}}\right)$ as modelled in (a) RACMO2, (b) MAR, and their difference (c) (MAR - RACMO2).

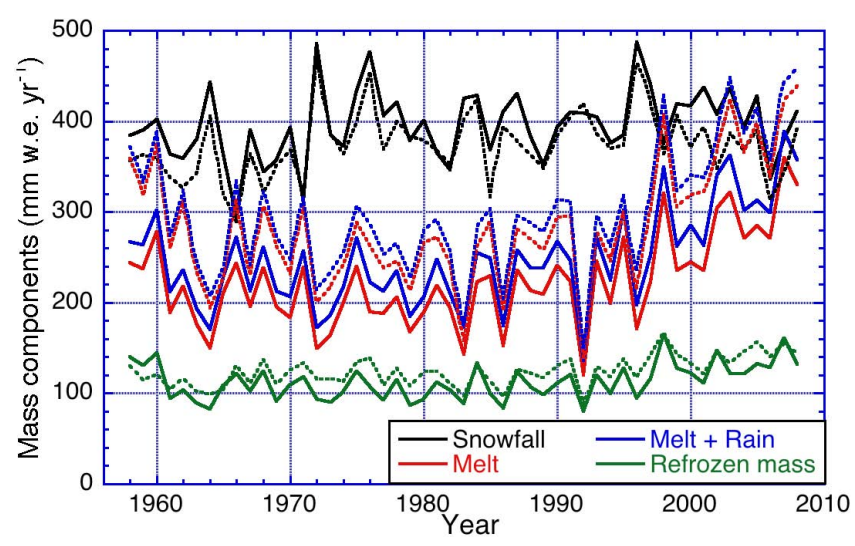

Fig. 2. Time series of ice sheet averaged annual sums of snowfall $(C)$, melt $(M)$, melt plus rain $\left(W_{\mathrm{r}}\right)$, and refrozen mass $\left(E_{\mathrm{r}}\right)$ as modelled in RACMO2 (solid lines) and MAR (dashed lines).

pronounced feature in Fig. 3a is the high snowfall over the southeast. The snowfall pattern is determined by the large scale circulation around Greenland and the ice sheet topography: the Icelandic Low advects moist oceanic air westward to the GrIS, where it rises steeply from sea level to $2.5 \mathrm{~km}$ height. Note that only a small part of the ice sheet receives on average more than $2 \mathrm{~m}$ w.e. per year and no point receives on average more than $5 \mathrm{~m}$ w.e. per year. Snow- fall in MAR is on average smaller $\left(366.9 \mathrm{~mm}\right.$ w.e. $\mathrm{yr}^{-1} \mathrm{vs}$. $391.1 \mathrm{~mm}$ w.e. $\left.\mathrm{yr}^{-1}\right)$, with largest differences $(>-70 \%)$ with RACMO2 on the southeast coast.

In RACMO2 about $50 \%$ (70\%) of the total melt (runoff) occurs below the equilibrium line along the ice margin (Fig. 3b), and about $8 \%(8 \%)$ within about $10 \mathrm{~km}$ of the equilibrium line. The widest melt zone is located in the west. Total melt (runoff) in MAR is larger than in RACMO (234.8 (135.7) $\mathrm{mm}$ w.e. $\mathrm{yr}^{-1}$ vs. $196.0(108.3) \mathrm{mm}$ w.e. $\mathrm{yr}^{-1}$ ), the spatial distribution is similar. Rainfall in both models is concentrated on the southern margins of the ice sheet (Fig. 3c). The percentage of the total precipitation falling as rain can be considerable (up to $50 \%$ ), and occasionally rain occurs at elevations over $2000 \mathrm{~m}$, especially on the southern part of the ice sheet. Therefore, taking rain into account may (locally) have a significant impact on the estimated refreezing (see Sect. 4.2).

The inter-annual variability in the ice sheet integrated mass balance components is considerable and similar for RACMO2 and MAR (Fig. 2). No significant trend in snowfall occurs over the period 1958-2008. In contrast, melt (and melt + rain) has increased significantly over the last $20 \mathrm{yr}$ (about $3 \% \mathrm{yr}^{-1}$ ), as has refreezing (about $1.5 \% \mathrm{yr}^{-1}$ ). With the shift of melt to ever higher elevations, melt water will not run off, but refreeze in the cold snow pack until the refreezing capacity has degraded to the point that runoff starts. 

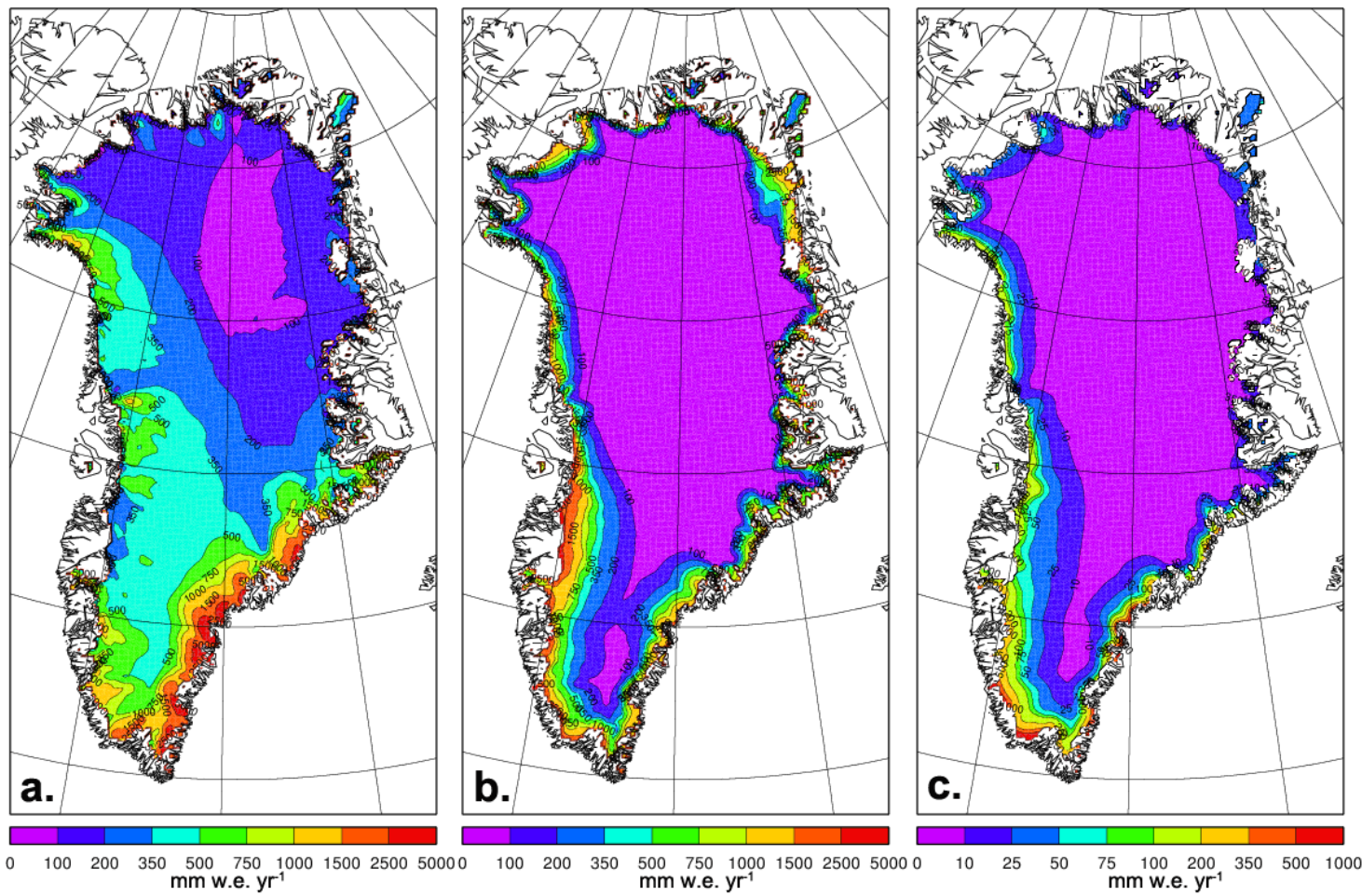

Fig. 3. Period (1958-2008) averaged anual sums of (a) snowfall $(C)$ (b) melt $(M)$, and (c) rain as modelled in RACMO2. Note the different scale in panel $\mathrm{c}$.

The surface temperature shows the well-known decrease of temperature with height and elevation (Fig. 4). The $-15^{\circ} \mathrm{C}$ isotherm corresponds to an altitude of about $1500 \mathrm{~m}$ (equilibrium line) on the western margin, and elsewhere ranges from sea level up to $2000 \mathrm{~m}$. The annual average temperature on the GrIS is $-24.3{ }^{\circ} \mathrm{C}$ (RACMO2), and varies between $-26.2^{\circ} \mathrm{C}$ and $-22.3^{\circ} \mathrm{C}$ (Fig. 5). MAR is on average $0.4^{\circ} \mathrm{C}$ warmer. Over the past $20 \mathrm{yr}$, surface temperature on the ice sheet has increased by about $2.5^{\circ} \mathrm{C}$; the first decade of the model period exhibits similarly high temperatures, although inter-annual variability was much larger than during the last decade.

\section{Results}

First a comparison will be made of the parameterizations as formulated in their original papers forced by and compared to both models, RACMO2 and MAR, in the absence of observations. Then the input parameters will be varied and the effect on calculated amount of refreezing discussed. In these tests the parameterizations will be forced with and evaluated against RACMO2 fields.

\subsection{Comparison}

\subsubsection{Time series}

Figures 2 and 6 show that the inter-annual variability in modelled and parameterized values of $E_{\mathrm{r}}$ are very similar for most methods. The absolute values, on the other hand, exhibit a large range around RACMO2 and MAR, with mean differences (Diff) ranging from $-70.2 \mathrm{~mm}$ w.e. $\mathrm{yr}^{-1}$ $(-56.4 \%)$ to $35.5 \mathrm{~mm}$ w.e. $\mathrm{yr}^{-1}(+31.4 \%)$ (Table 2). The average difference between RACMO2 and MAR is small (4.9 mm w.e. $\mathrm{yr}^{-1}$ ) and is only partly the result of differences in snow model formulation. The atmospheric forcing in RACMO2 and MAR differs as well. Over the largest part of the ice sheet, i.e. the higher parts, $E_{\mathrm{r}}$ is limited by $W_{\mathrm{r}}$. In these higher areas the correspondence between the models and the parameterizations is good (see next Section). In the models, because of this, a strong correlation exists between ice sheet annual averaged $M$ (or $M+$ rain) and $E_{\mathrm{r}}$. The differences in temporal variability and absolute amount in Fig. 6 are therefore mainly determined by the lower areas of the ice sheet, where $E_{\mathrm{r}}$ is at least partly determined by $P_{\mathrm{r}}$.

In Fig. 6, Pf1991 and HdW1999 show the lowest, and Wr2007 the highest refreezing values. The low values for Pf1991 are mainly the result of the mask formulation, which only takes into account refreezing at elevations above the runoff line, while below this line all water is assumed to 


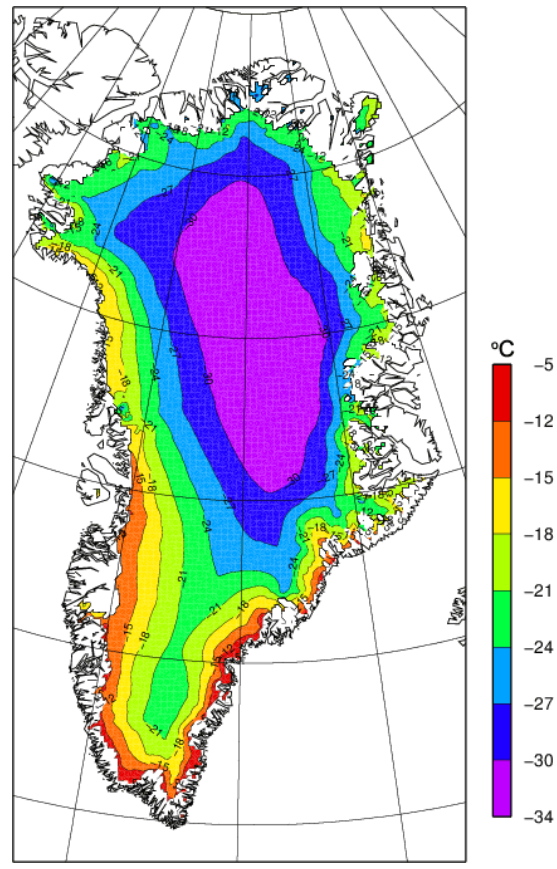

Fig. 4. The period (1958-2008) average annual mean surface temperature $\left(T_{\mathrm{S}}\right)$ as modelled in RACMO2. The $-15^{\circ} \mathrm{C}$ isotherm corresponds to an altitude of about $1500 \mathrm{~m}$ (equilibrium line) in the ablation area on the western margin, and elsewhere ranges from sea level up to $2000 \mathrm{~m}$.

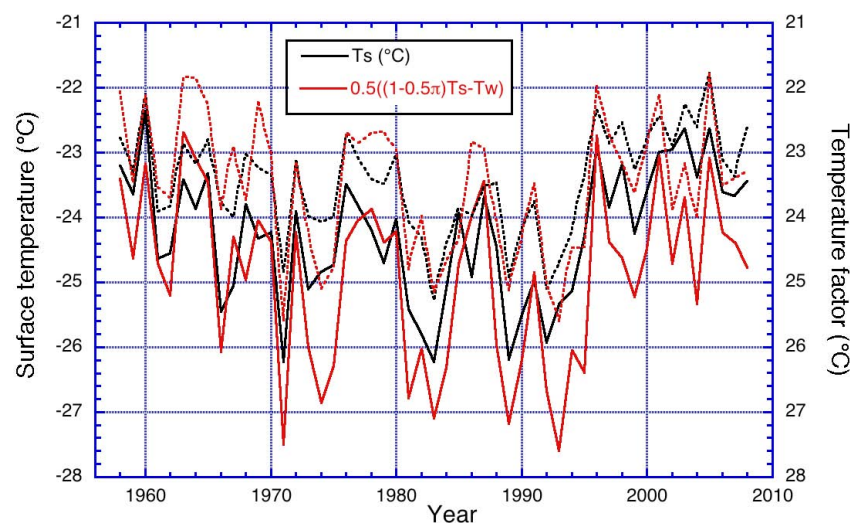

Fig. 5. Time series of ice sheet averaged annual averaged surface temperature $\left(T_{\mathrm{S}}\right.$, black) and temperature factor used in Eq. (7) (red) based on RACMO2 (solid lines) and MAR (dashed lines) fields. Note the reversed axis on the right hand side.

run off. Although JH2000 is the most physically based parameterization, and in that sense best comparable to the models, the refreezing differs significantly from RACMO2 and even more from MAR. The absolute amount compared to RACMO2 (MAR) is lower by $17 \%(40 \%)$, as is the temporal variability (Std1), by $31 \%(45 \%)$. Of all parameterizations the average difference with $\mathrm{RACMO} 2$ and
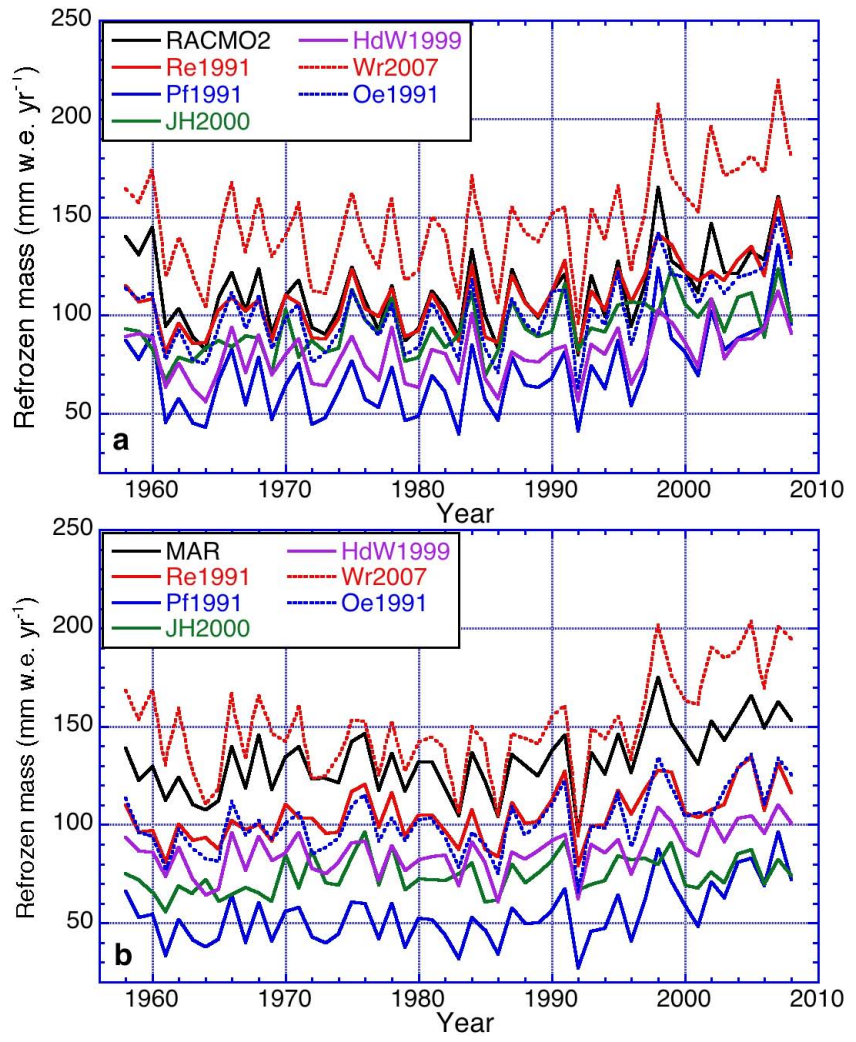

Fig. 6. Time series of ice sheet averaged annual sums of refrozen mass $\left(E_{\mathrm{r}}\right)$ as modelled using the presented parameterizations. Using (a) RACMO2 and (b) MAR input fields.

MAR is smallest in Re1991 (Diff $=-4.2 \mathrm{~mm}$ w.e. $\mathrm{yr}^{-1}$ and $-19.5 \mathrm{~mm}$ w.e. $\mathrm{yr}^{-1}$, respectively, Table 2). In Re1991, refreezing is determined by either the annual average snowfall $C$, or melt $M$ (Eqs. 2 and 3). The value of $P_{\max }=0.6$ is obviously well chosen to represent the fraction of $C$ that is refrozen in the area where $P_{\max } \cdot C$ limits the amount of refreezing.

Oe1991 also corresponds well with RACMO2 and MAR (Diff $=11.3 \mathrm{~mm}$ w.e. $\mathrm{yr}^{-1}$ and $22.6 \mathrm{~mm}$ w.e. $\mathrm{yr}^{-1}$, respectively, Table 2). This is surprising since the formulation of $E_{\mathrm{r}}$ in Oe1991 is fairly different from the models. Furthermore, we do not apply Oe1991 as it was original intended. Oe1991 was designed to be used in an energy balance model, were refreezing changes the snow temperature, and thereby affecting refreezing in the next time step. This interaction is not allowed in the present application. Furthermore, we use monthly data as input fields, instead of $15 \mathrm{~min}$ time steps in Oe1991 (Eq. 10), not taking into account variability on shorter time scales. The reason that Oe1991 results are similar to the models is twofold: firstly, by limiting $E_{\mathrm{r}}$ to the annual amount of total precipitation $P_{\text {tot }}$, the possible overestimation of refreezing in the ablation area, where ice surfaces in the course of the melt season, is prevented. Secondly, as is 
Table 2. Statistics of the different parameterizations compared to RACMO2 (second part) and MAR (third part). First part compares RACMO2 and MAR (MAR-RACMO2) for points where both models define ice. Mean ${ }^{1}=$ ice sheet and period (1958-2008) averaged annual $E_{\mathrm{r}}$; Diff ${ }^{2}=$ difference of Mean with an RCM; $\operatorname{Std} 1^{3}=$ a measure for the temporal variability; $\mathrm{Std}_{2}{ }^{4}=\mathrm{a}$ measure for the spatial variability in the difference. All values are expressed in mm w.e. $\mathrm{yr}^{-1}$.

\begin{tabular}{lrrrr}
\hline Param. & Mean & Diff $^{2}$ & Std1 $^{3}$ & Std2 $^{4}$ \\
\hline RACMO2 & 107.9 & & 19.8 & \\
MAR & 112.7 & 4.9 & 16.6 & 40.9 \\
\hline RACMO2 & 112.9 & & 19.8 & \\
Re1991 & 108.7 & -4.2 & 17.1 & 85.9 \\
Pf1991 & 70.3 & -42.6 & 20.6 & 142.8 \\
JH2000 & 93.4 & -19.4 & 13.6 & 129.1 \\
HdW1999 & 80.1 & -32.8 & 13.5 & 89.5 \\
Wr2007 & 148.4 & 35.5 & 26.5 & 113.0 \\
Oe1991 & 101.6 & -11.3 & 18.5 & 74.3 \\
\hline MAR & 124.4 & & 16.6 & \\
Re1991 & 104.9 & -19.5 & 13.1 & 54.1 \\
Pf1991 & 54.3 & -70.2 & 14.7 & 136.8 \\
JH2000 & 74.2 & -50.3 & 9.2 & 102.5 \\
HdW1999 & 86.2 & -38.2 & 11.6 & 92.9 \\
Wr2007 & 150.8 & 26.4 & 25.3 & 89.6 \\
Oe1991 & 101.8 & -22.6 & 15.6 & 77.7 \\
\hline
\end{tabular}

$$
\begin{aligned}
& { }^{1} \text { Mean }=\frac{1}{n} \frac{1}{n y r} \sum_{i, j} \sum_{y r} E_{\mathrm{r}}(i, j, y r), i, j \text { is the ice sheet grid } \\
& \text { point at year } y r \text { in period 1958-2008, } n \text { is the total number of grid } \\
& \text { points, and } n y r \text { is the total number of years, for any } \\
& \text { parameterization or RCM. } \\
& { }^{2} \text { Diff }=\text { Mean - Mean } \\
& \mathrm{RCM} \\
& { }^{3} \mathrm{Std} 1=\sqrt{\frac{1}{n y r} \sum_{y r}\left[\left(\frac{1}{n} \sum_{i, j} E_{\mathrm{r}}(i, j, y r)\right)-\mathrm{Mean}\right]^{2}} \\
& { }^{4} \mathrm{Std} 2= \\
& \sqrt{\frac{1}{n} \sum_{i, j}\left[\left(\frac{1}{n y r} \sum_{y r} E_{\mathrm{r}}(i, j, y r)-\frac{1}{n y r} \sum_{y r} E_{\mathrm{r}, \mathrm{RCM}}(i, j, y r)\right)-\mathrm{Diff}\right]^{2}}
\end{aligned}
$$

the case for the other parameterizations, $W_{\mathrm{r}}$ is the limiting factor over the remainder of the ice sheet, not $P_{\mathrm{r}}$.

The differences between the parameterizations when forced with RACMO2 or MAR are small (except for Pf1991 and JH2000) and can be explained by the on average higher amount of $M$, higher $T_{\mathrm{s}}$ and lower amount of $C$ in MAR. The larger differences in Pf1991 and JH2000 are due to the higher $M$ and lower $C$, both resulting in a smaller second term on the r.h.s. of Eqs. (4) and (5) and as a result lower amount of refreezing.

\subsubsection{Areal distribution}

The spatial fields of $E_{\mathrm{r}}$ of RACMO2 and MAR show reasonable agreement $\left(\mathrm{Std} 2=\sim 40.9 \mathrm{~mm}\right.$ w.e. $\mathrm{yr}^{-1}$, Table 2$)$. The visible regional differences (Fig. 1c) can partly be explained by differences in snow model formulation and partly by the atmospheric forcing. Over most of the ice sheet MAR ex- hibits more refreezing than RACMO2, which is due to the larger value for irreducible water content in MAR (6\% vs. $2 \%$ ). The different albedo formulations result in differences in timing and amount of melt. This is caused by the density of the snow surface (which determines the albedo in RACMO2) reacting slower to temperature changes than the surface snow grain characteristics (which determine the albedo in MAR). Enhanced by the melt-albedo feedback, melt occurs earlier and in slightly larger amounts in MAR. This signal is enhanced by the sub freezing snow temperatures in spring, and by the larger delay between runoff and meltwater production in MAR compared to RACMO2. In MAR, the meltwater produced during the warmest hours of the day can refreeze during the following night, while in RACMO2 the meltwater immediately runs off. In the areas where bare ice is exposed in the melt season, RACMO2 shows less refreezing than MAR due to a smaller minimum thickness of the uppermost snow layer in MAR $(<1 . \mathrm{cm}$ vs. $\sim 6.5 \mathrm{~cm})$. As a result, snow disappears earlier and it takes longer to form a new layer of snow on ice in RACMO2. In addition, the bare ice albedo is lower in MAR (0.4-0.45 vs. $0.45-0.5)$ resulting in more melt production. In the areas where more refreezing occurs in RACMO2 compared to MAR, also more melt occurs, which in the north and southeast is the result of higher temperatures in RACMO2.

Comparing the spatial distributions based on the parameterizations with the RCM refreezing shows significant differences (Fig. 7, Table 2). Note that Fig. 7 presents the spatial differences with respect to RACMO2. Spatial differences with respect to MAR are similar. In general, all parameterizations show small differences with the models in the higher parts of the ice sheet $\left(<10 \mathrm{~mm}\right.$ w.e.), where $W_{\mathrm{r}}$ is the limiting factor for refreezing. For the parameterizations that take rain into account, the difference is zero (Fig. 7c, d, e), whereas the others show small negative differences in the order of the annual amount of rain. In the higher parts of the ablation zones refreezing in RACMO2 and MAR is reasonably high, which is the result of multiple cycles of melt/refreezing. These are not explicitly taken into account in the parameterizations. The largest differences are once more found at the margins of the ice sheet, where most of the refreezing occurs. In these areas $E_{\mathrm{r}}$ is mainly determined by $P_{\mathrm{r}}$, not $W_{\mathrm{r}}$. The largest underestimation of refreezing compared to the models is found in Pf1991, which does not allow refreezing to occur below the runoff line, i.e. along the ice margins. Differences between MAR and RACMO2 forced parameterizations are explained by differences in $W_{\mathrm{r}}$ for HdW1999, Wr2007 and Oe1991, while for the others the differences in $C$ and $M$ in determining $P_{\mathrm{r}}$ also play a role.

For the parameterizations that depend on the annual amount of snowfall (Re1991, Pf1991, JH2000), $E_{\mathrm{r}}$ is larger than the models along the south and southeastern margins of the ice sheet (Fig. 7a, b, c) where the amount of snowfall is high (Fig. 3a). In these areas, the use of snowfall results in a large $P_{\mathrm{r}}$, and consequently $E_{\mathrm{r}}$ is limited by $W_{\mathrm{r}}$ and not by $P_{\mathrm{r}}$. 

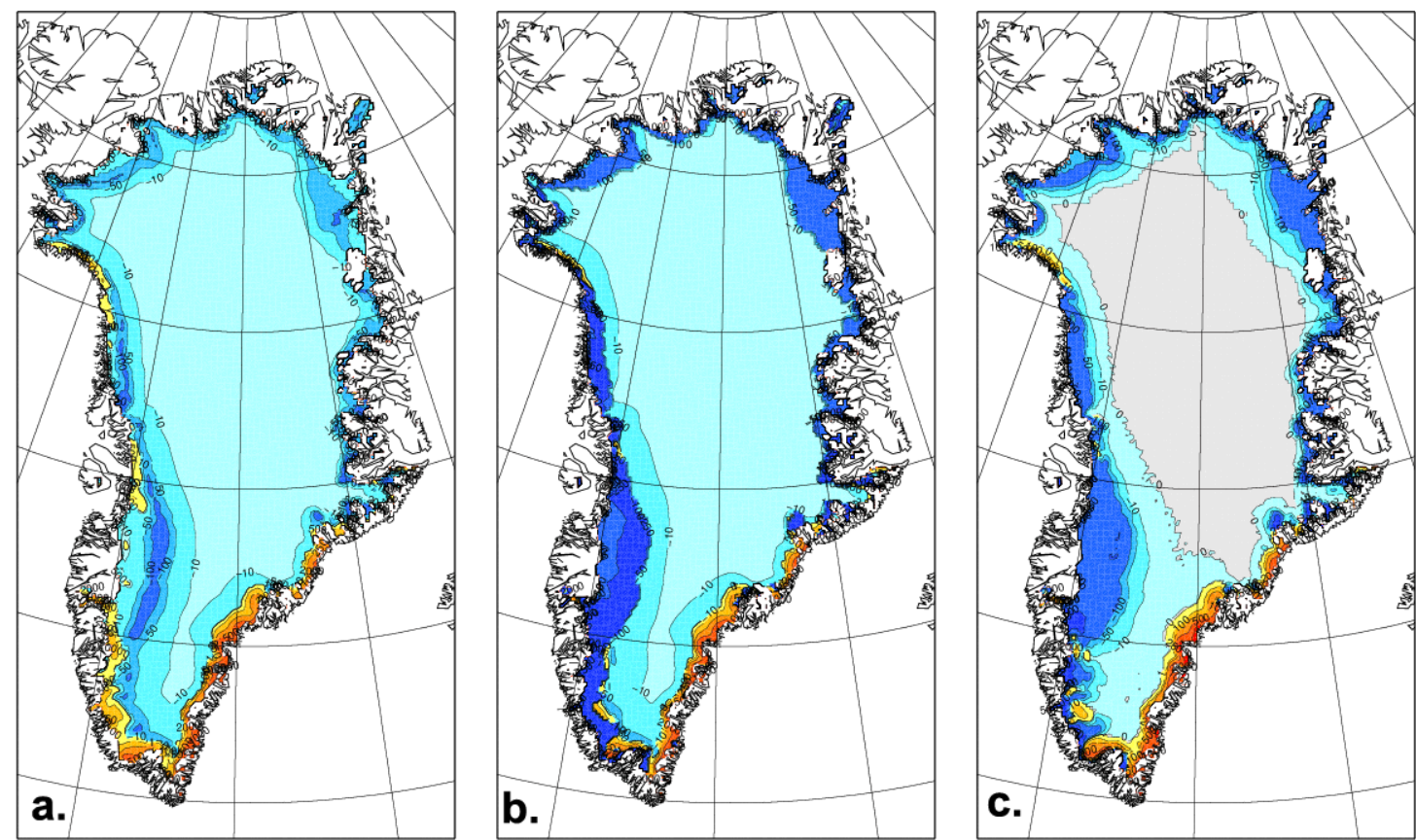

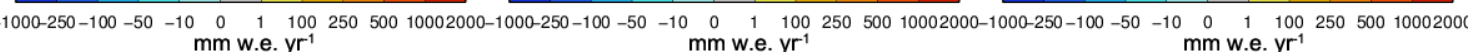
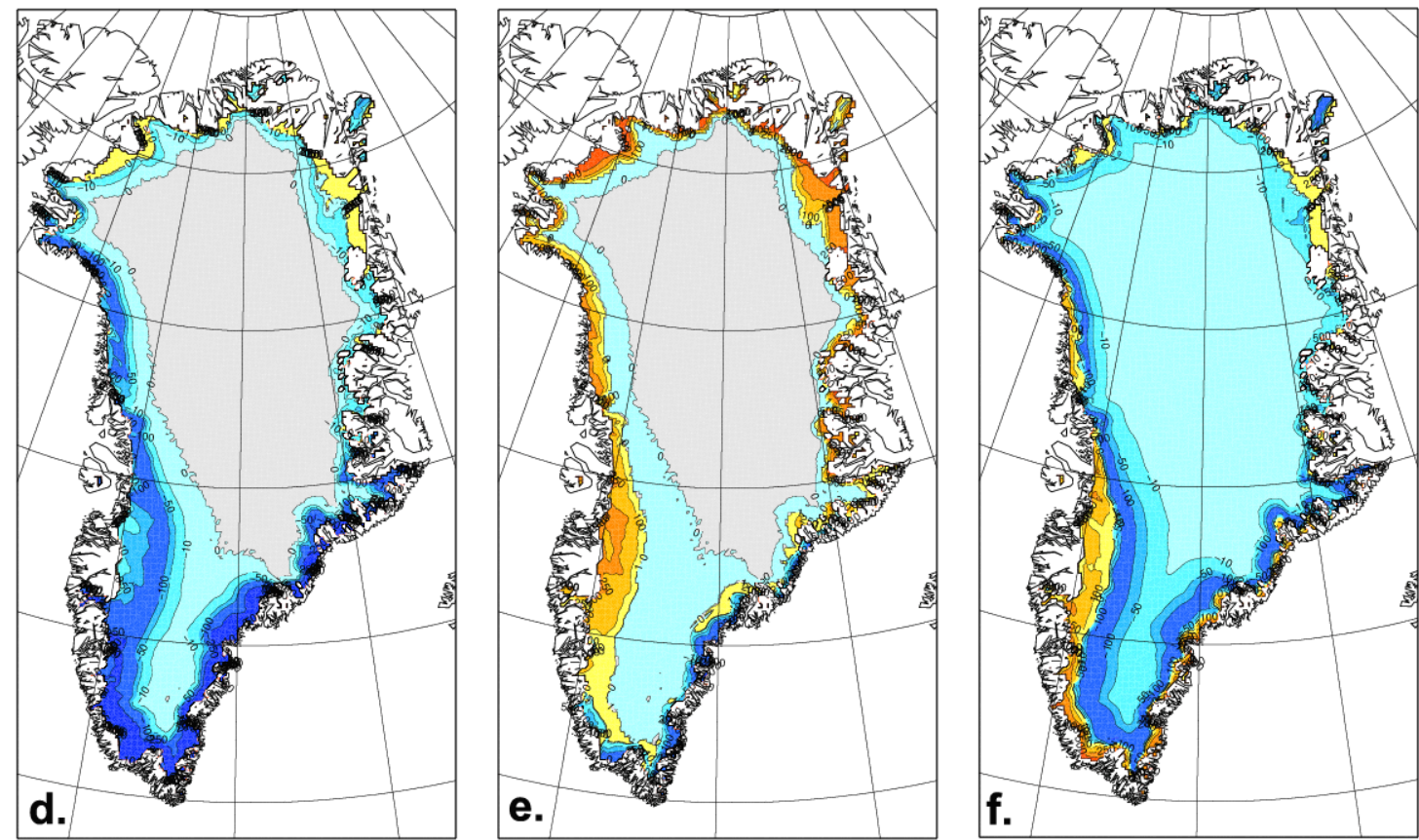

$-1000-250-100-50-10 \quad 0 \quad 1 \quad 100$

Fig. 7. Difference between RACMO2 modelled refrozen mass $\left(E_{\mathrm{r}}\right)$ and parameterized amount (Param. - RACMO2). (a) Re1991, (b) Pf1991, (c) JH2000, (d) HdW1999, (e) Wr2007, (f) Oe1991. 
In RACMO2 and MAR, $P_{\mathrm{r}}$ is not set by a given snow depth and determined more by the modelled snow temperature, resulting in lower values of $E_{\mathrm{r}}$.

HdW1999 make use of a fixed depth of $2 \mathrm{~m}$ w.e. for the thermally active layer. On the south and southeast margin, this value is smaller than snowfall $C$ resulting in lower values of $P_{\mathrm{r}}$, limiting $E_{\mathrm{r}}$. Although Wr2007 also uses a constant value of the thermally active layer ( $5 \mathrm{~m}$ w.e.), this value is on average larger than $C$ and therefore does not explain the smaller values of $E_{\mathrm{r}}$ on the southeast margin. The smaller difference between the models and Wr2007 in these areas is likely caused by a different representation of the cold content by using the integrated area between standard profiles of the winter and summer snow temperature instead of using the annual average temperature.

Based on Table 2, the best correspondence with RACMO2 (lowest Std2) is found for Oe1991, followed by Re1991 and HdW1999. For MAR the best correspondence is found for Re1991, followed by Oe1991 and HdW1999. Although the principles on which Pf1991 and especially JH2000 are based are the most similar to RACMO2 and MAR, the spatial correspondence is poorest (highest Std2 values, Table 2). Note that the spatial correspondence between RACMO2 and MAR is better, and the average difference between them smaller than compared to any of the parameterizations (Diff $=4.9 \mathrm{~mm}$ w.e. $\mathrm{yr}^{-1}, \mathrm{Std} 2=\sim 40.9 \mathrm{~mm}$ w.e. $\mathrm{yr}^{-1}$, Table 2). Only Re1991 forced with RACMO2 results in a smaller Diff. The good agreement between RACMO2 and MAR is especially interesting since the differences between them are only partly the result of differences in the snow model and partly due to differences in atmospheric forcing. In contrast, differences between parameterizations and RACMO2/MAR are solely due to the refreezing formulation.

\subsection{Sensitivity experiments}

We investigate the impact on the calculated amount of refreezing of varying the different parameters in the parameterizations: the period of averaging, the in- or exclusion of rain, as well as more model specific parameters such as the depth of the thermally active layer, temperature, yes or no capillary water, and density. The tests are described below and statistics are presented in Table 3. In these tests forcing field come from RACMO2 and the results will be compared to refreezing as calculated in RACMO2.
Table 3. Tests of the input variables of the parameterizations. RACMO2 input fields are used. Reference statistics are given in Table 2. Headings are as in Table 2, Diff and Std2 are with respect to RACMO2 refreezing, test refers to change compared to reference, numbers between brackets denote sections where experiments are discussed.

\begin{tabular}{|c|c|c|c|c|c|}
\hline Param. & Test & Mean & Diff & Std 1 & Std2 \\
\hline \multicolumn{6}{|c|}{ Averaging period (Sect. 4.2.1) } \\
\hline Re1991 & Period & 111.0 & -1.9 & 18.0 & 90.2 \\
\hline Pf1991 & Annual & 66.6 & -46.4 & 10.3 & 114.5 \\
\hline JH2000 & Period & 115.0 & 2.1 & 42.6 & 135.3 \\
\hline HdW1999 & Period & 103.8 & -9.1 & 39.0 & 80.1 \\
\hline Wr2007 & Annual & 148.1 & 35.2 & 26.7 & 112.6 \\
\hline \multicolumn{6}{|c|}{ Including rain or not (Sect. 4.2.2) } \\
\hline $\operatorname{Re} 1991$ & $M+$ Rain & 116.9 & 4.1 & 17.2 & 106.0 \\
\hline Pf1991 & $M+$ Rain & 76.1 & -36.8 & 21.7 & 166.7 \\
\hline JH2000 & $M$ & 82.4 & -30.5 & 12.5 & 103.1 \\
\hline HdW1999 & $M$ & 77.0 & -35.9 & 13.6 & 89.1 \\
\hline Wr2007 & $M$ & 141.4 & 28.5 & 26.5 & 113.0 \\
\hline Oe1991 & $M+$ Rain & 109.2 & -3.7 & 20.1 & 90.2 \\
\hline
\end{tabular}

Thickness $d_{\text {ice }}$ (Sect. 4.2.3) and capillary water (Sect. 4.2.4)

\begin{tabular}{|c|c|c|c|c|c|}
\hline Pf1991 & no cap. water ${ }^{1}$ & 6.1 & -106.8 & 4.6 & 147.1 \\
\hline JH2000 & $d_{\text {ice }}=2 \mathrm{~m}$ & 124.5 & 11.6 & 17.7 & 112.1 \\
\hline JH2000 & $d_{\text {ice }}=3 \mathrm{~m}$ & 139.6 & 28.6 & 20.6 & 115.9 \\
\hline JH2000 & $d_{\text {ice }}=5 \mathrm{~m}$ & 164.6 & 51.7 & 26.1 & 141.9 \\
\hline HdW1999 & $C$ & 29.9 & -83.0 & 3.7 & 115.6 \\
\hline HdW1999 & $d_{\text {ice }}=1 \mathrm{~m}$ & 48.6 & -64.3 & 7.7 & 114.0 \\
\hline HdW1999 & $d_{\text {ice }}=3 \mathrm{~m}$ & 103.8 & -9.1 & 17.7 & 79.1 \\
\hline Wr2007 & $C$ & 30.6 & -82.3 & 3.7 & 115.3 \\
\hline Wr2007 & $d_{\text {ice }}=3 \mathrm{~m}$ & 111.3 & -1.5 & 19.5 & 79.2 \\
\hline Wr2007 & $d_{\text {ice }}=6 \mathrm{~m}$ & 162.4 & 49.5 & 29.5 & 136.2 \\
\hline
\end{tabular}

Density (Sect. 4.2.5)

\begin{tabular}{llrrrl}
\hline Pf1991 & $\rho_{\mathrm{pc}}=960 \mathrm{~kg} \mathrm{~m}^{-3}$ & 72.4 & -40.5 & 21.0 & 142.3 \\
Pf1991 & $\rho_{\mathrm{pc}}=830 \mathrm{~kg} \mathrm{~m}^{-3}$ & 67.6 & -45.5 & 20.1 & 143.2 \\
Pf1991 & $\rho_{\mathrm{f}}=450 \mathrm{~kg} \mathrm{~m}^{-3}$ & 54.1 & -58.7 & 17.5 & 144.7 \\
Pf1991 & $\rho_{\mathrm{f}}=150 \mathrm{~kg} \mathrm{~m}^{-3}$ & 84.4 & -28.5 & 23.1 & 139.0 \\
JH2000 & $\rho_{\mathrm{pc}}=900 \mathrm{~kg} \mathrm{~m}^{-3}$ & 92.2 & -20.7 & 13.4 & 127.7 \\
$\mathrm{JH} 2000$ & $\rho_{\mathrm{pc}}=830 \mathrm{~kg} \mathrm{~m}^{-3}$ & 90.5 & -22.4 & 13.1 & 125.8 \\
$\mathrm{JH} 2000$ & $\rho_{\mathrm{f}}=450 \mathrm{~kg} \mathrm{~m}^{-3}$ & 83.2 & -29.6 & 11.9 & 117.7 \\
$\mathrm{JH} 2000$ & $\rho_{\mathrm{f}}=150 \mathrm{~kg} \mathrm{~m}^{-3}$ & 101.6 & -11.3 & 15.1 & 138.5 \\
$\mathrm{JH} 2000$ & $\rho_{f}\left(T_{S}\right)^{2}$ & 85.6 & -27.3 & 12.3 & 113.8 \\
\hline
\end{tabular}

Temperature (Sect. 4.2.6)

\begin{tabular}{llrrrr}
\hline Pf1991 & $T_{\mathrm{s}}=$ RACMO2 $^{3}$ & 70.1 & -42.7 & 20.6 & 142.2 \\
Pf1991 & $T_{\mathrm{f}}=-10$ & 69.1 & -43.7 & 20.4 & 143.1 \\
Pf1991 & $T_{\mathrm{f}}=-20$ & 71.1 & -41.8 & 20.7 & 142.7 \\
JH2000 & $T_{\mathrm{S}}+5$ & 91.2 & -21.6 & 13.4 & 130.1 \\
JH2000 & $T_{\mathrm{S}}-5$ & 95.5 & -17.3 & 13.9 & 128.4 \\
HdW1999 & $T_{\mathrm{S}}+5$ & 64.2 & -48.7 & 11.0 & 105.5 \\
HdW1999 & $T_{\mathrm{S}}-5$ & 93.8 & -19.1 & 15.7 & 77.6 \\
Wr2007 & $T_{\mathrm{S}}+5, T_{\mathrm{W}}+5$ & 131.2 & 18.3 & 23.6 & 99.1 \\
Wr2007 & $T_{\mathrm{S}}-5, T_{\mathrm{W}}+5$ & 162.8 & 49.9 & 29.1 & 132.3 \\
Oe1991 & $T_{\mathrm{S}}+5$ & 24.1 & -88.8 & 5.4 & 135.1 \\
Oe1991 & $T_{\mathrm{S}}-5$ & 110.4 & -2.5 & 20.8 & 91.2 \\
\hline
\end{tabular}

\begin{tabular}{llrrrr}
\hline$P_{\max }$ (Sect. 4.2.7) & & & & & \\
\hline$R e 1991$ & $P_{\max }=0.5$ & 98.8 & -14.1 & 14.9 & 80.2 \\
$R e 1991$ & $P_{\max }=0.7$ & 116.8 & 3.9 & 19.0 & 92.2 \\
\hline
\end{tabular}

\footnotetext{
${ }^{1}$ Second term r.h.s. Eq. (4) is 0.

2 Reeh et al. (2005).

${ }^{3}$ Period averaged per grid point.
} 

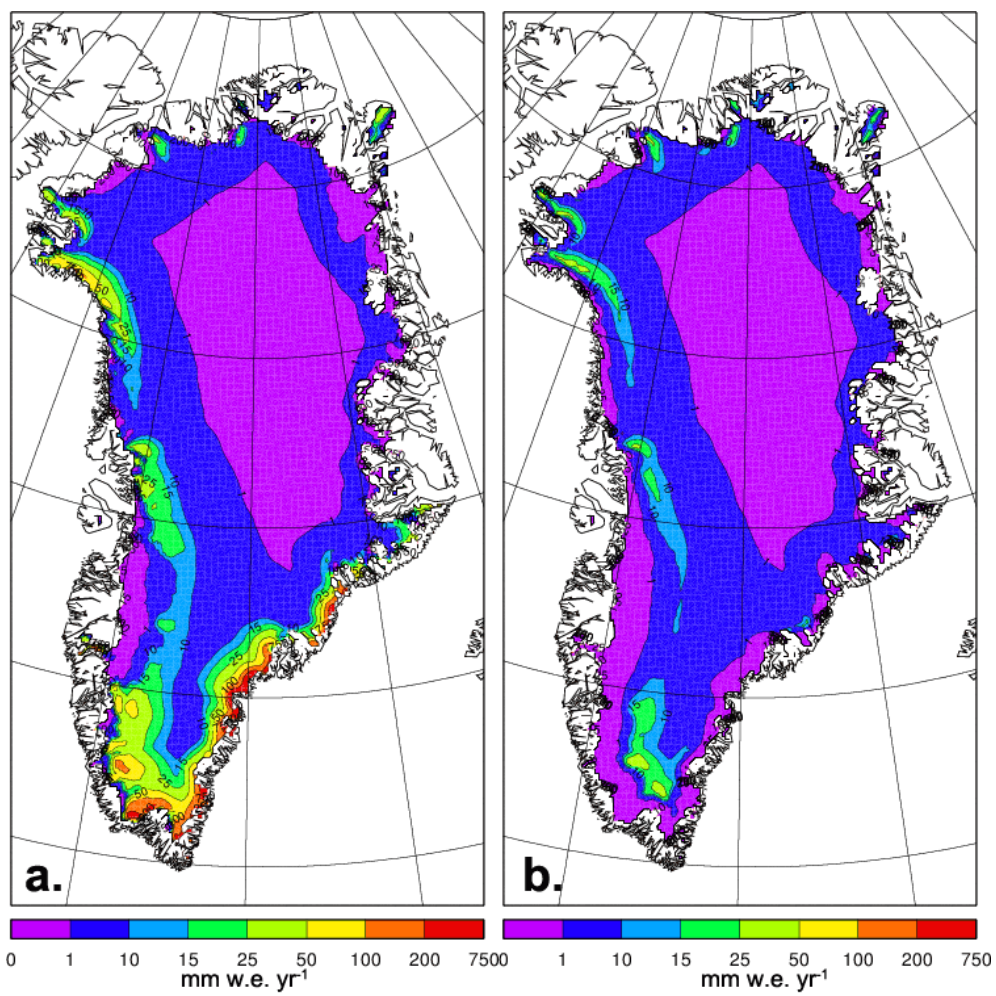

Fig. 8. Difference in refreezing when including rain in $W_{\mathrm{r}}($ Yes - No) for JH2000 (a) and HdW1999 (b), using RACMO2 input fields.
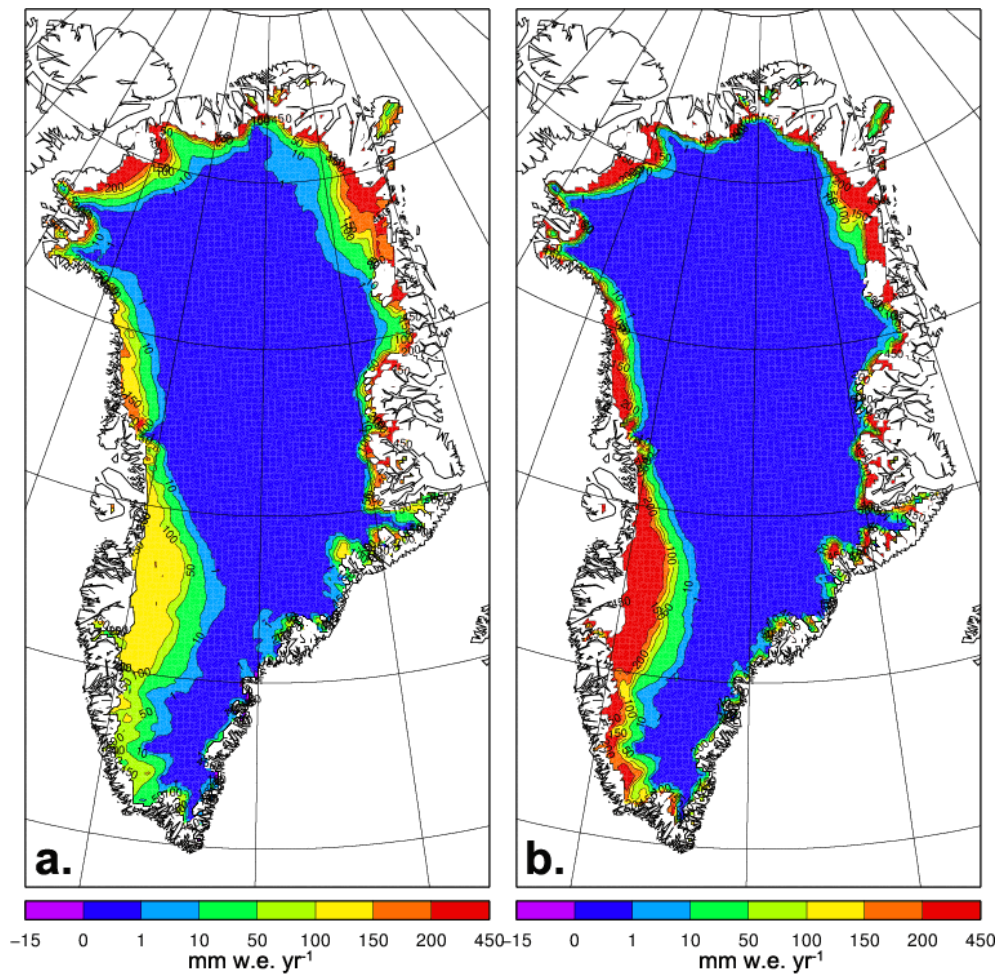

Fig. 9. Difference in refreezing when varying the depth of the thermally active layer $\left(d_{\text {ice }}\right)$ in JH2000 (Eq. 5 ). (a) $d_{\text {ice }}=2 \mathrm{~m}$ minus $C$, (b) $d_{\text {ice }}=5 \mathrm{~m}$ minus $2 \mathrm{~m}$, using RACMO2 input fields. 

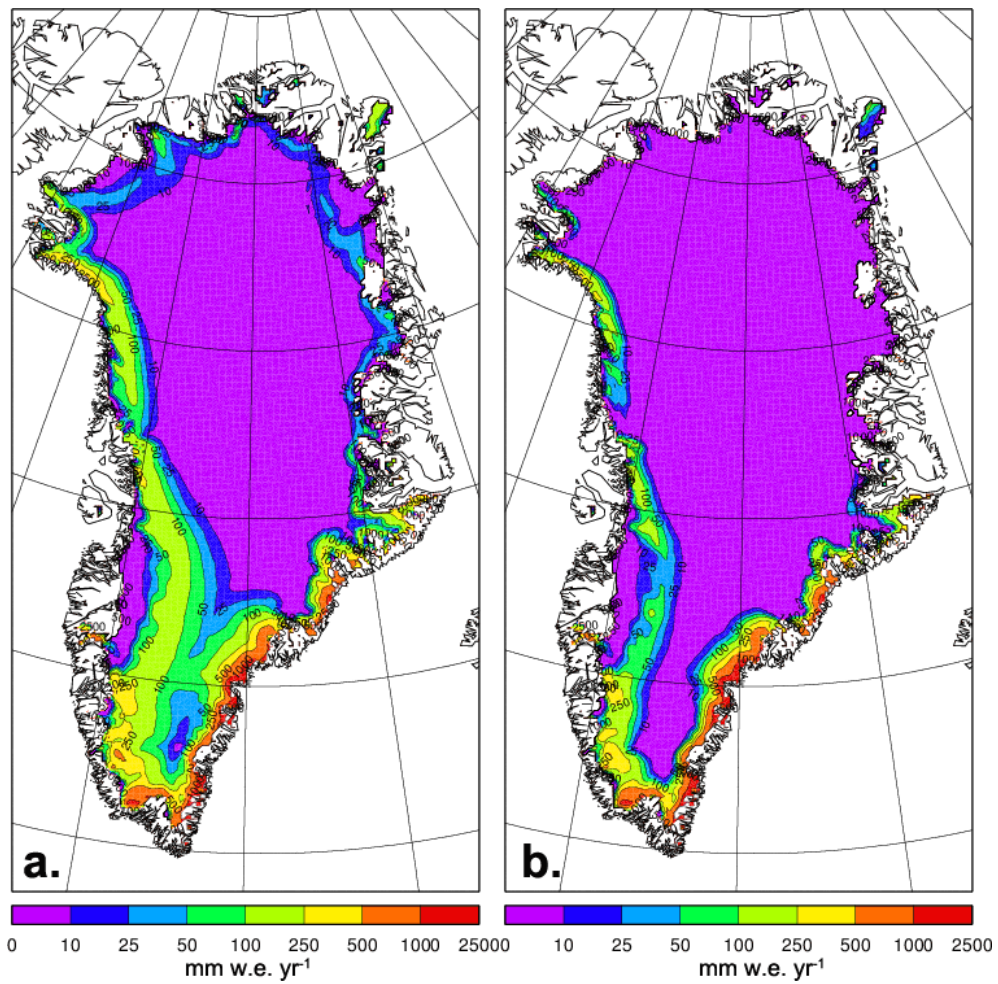

Fig. 10. Difference in refreezing when including capillary water in $P_{\mathrm{r}}$. Both panels show JH2000 minus HdW1999 (Yes - No). (a) $d_{\text {ice }}=C$, (b) $d_{\text {ice }}=2 \mathrm{~m}$, using RACMO2 input fields.

Table 4. Statistics of the different parameterizations compared to RACMO2 after tuning. Headings are as in Table 2, comments refers to changes in parameter setting compared to the reference (Table 2). In all experiments Mean $=112.9 \mathrm{~mm}$ w.e. $\mathrm{yr}^{-1}$ and Diff $=0.0 \mathrm{~mm}$ w.e. $\mathrm{yr}^{-1}$.

\begin{tabular}{lrrl}
\hline Param. & Std1 & Std2 & Comments \\
\hline RACMO2 & 19.8 & & \\
Re1991 & 18.1 & 89.0 & $P_{\max }=0.65$ \\
Re1991 & 16.4 & 101.7 & $P_{\max }=0.56,+$ Rain \\
Pf1991 & 15.5 & 116.7 & $d_{\text {ice }}=4.46 \mathrm{~m}$ w.e. $\quad \rho_{\mathrm{pc}}=$ \\
& & & $960 \mathrm{~kg} \mathrm{~m}^{-3}, \quad T_{\mathrm{f}}=-24.3^{\circ} \mathrm{C}$, \\
& & & annual averages, including rain \\
JH2000 & 15.9 & 113.9 & $d_{\text {ice }}=1.45 \mathrm{~m}$ w.e. \\
JH2000 & 16.5 & 121.5 & $d_{\text {ice }}=3.9 \cdot C$ \\
HdW1999 & 19.3 & 79.9 & $d_{\text {ice }}=3.45 \mathrm{~m}$ w.e. \\
HdW1999 & 17.2 & 67.4 & $d_{\text {ice }}=6.29 \cdot C$ \\
Wr2007 & 19.7 & 79.6 & $d_{\text {ice }}=3.07 \mathrm{~m}$ w.e. \\
Wr2007 & 18.8 & 91.6 & $d_{\text {ice }}=6.37 \cdot C$ \\
Oe1991 & 21.1 & 97.2 & $T_{\mathrm{s}}-0.37,+$ Rain \\
\hline
\end{tabular}

1 only in first term r.h.s. Eq. (5).

\subsubsection{Annual or period averages}

The parameterizations presented in Sect. 2 are based on either annual average values of $C, M$ and/or $T_{\mathrm{s}}$, or period mean (1958-2008) annual values (except Oe1991). The result is an annual $P_{\mathrm{r}}$ that is either constant throughout the calculated period, or annually variable. The latter is the physically most correct approach and applied by Re1991, JH2000 and HdW1999. Pf1991 and Wr2007 make use of period average $P_{\mathrm{r}}$ (Table 1). Pf1991 motivated his choice by limited available information, while $\mathrm{Wr} 2007$ based their parameterization on typical profiles of $T_{\mathrm{sn}}$ at the end of winter and summer that were best represented by multi-year averages of $T_{\mathrm{s}}$ and $T_{\mathrm{w}}$ determined from snow/ice temperature profile measurements.

In general, using period averages results in more refreezing and larger temporal variability (Table 1). Especially the inter-annual variability in Pf1991 depends heavily on whether a period average or annual average mask is used (Table 3): inter-annual variability is much larger when using a period-averaged mask. This is due to the fact that in Pf1991 the variability is determined by the variability in the melt, which is compensated by changes in the mask if annual values are used: more/less melt results in a smaller/larger area with refreezing. Results of Wr2007 and Re1991 on the other hand are less sensitive to this choice. For Wr2007 this is 


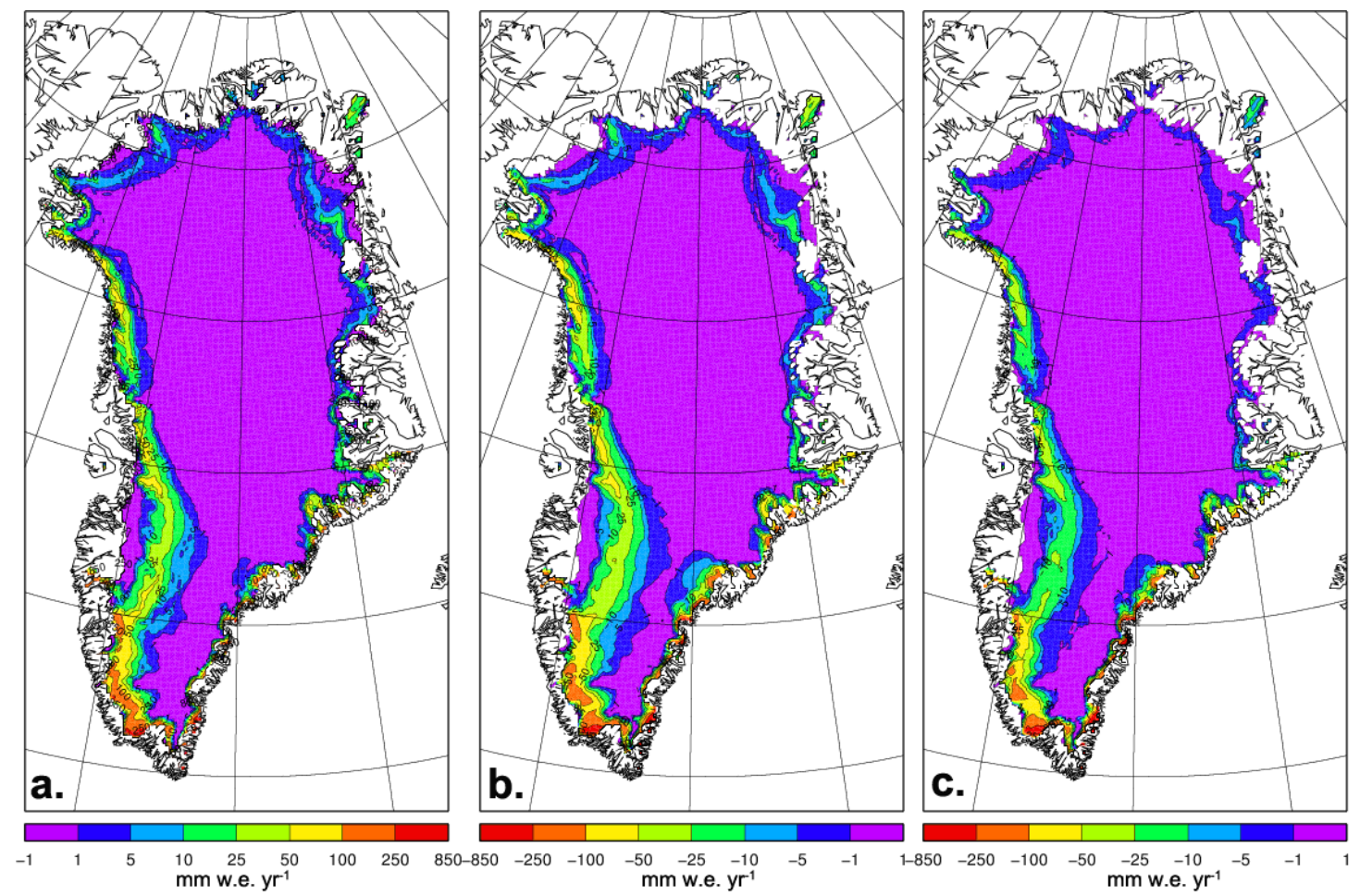

Fig. 11. Difference in refreezing when changing the density factor in JH2000 by changing $\rho_{\mathrm{f}}=300 \mathrm{~kg} \mathrm{~m}^{-3}$ (Eq. 5) to (a) $\rho_{\mathrm{f}}=150 \mathrm{~kg} \mathrm{~m}^{-3}$, (b) $\rho_{\mathrm{f}}=450 \mathrm{~kg} \mathrm{~m}^{-3}$, and (c) $\rho_{\mathrm{f}}\left(T_{\mathrm{S}}\right)$ (Reeh et al., 2005) (test minus reference), using RACMO2 input fields. Note the reversed color scales in panels (b) and (c).

explained by the fact that with $d_{\text {ice }}=5 \mathrm{~m}$ w.e., the refreezing over most part of the ice sheet is limited by $W_{\mathrm{r}}$ and not by $P_{\mathrm{r}}$. Thus, as long as changes in $P_{\mathrm{r}}$ do not result in a significant larger area where $P_{\mathrm{r}}$ exceeds $W_{\mathrm{r}}, E_{\mathrm{r}}$ will not change much when changing $P_{\mathrm{r}}$. In $\operatorname{Re} 1991 P_{\mathrm{r}}$ is determined by $C$. Using a period average $C$ results in a larger dependency on $M$. Using period averages, HdW1999 and JH2000 are also more determined by variations in $M$. In these parameterizations the correspondence with RACMO2 increases due to the correlation between $M$ and $E_{\mathrm{r}}$ in RACMO2. Note that HdW1999, which is a parameterization very similar to $\mathrm{Wr} 2007$, is more sensitive to changes in $P_{\mathrm{r}}$. This is caused by their choice of $d_{\text {ice }}=2 \mathrm{~m}$ w.e. leading to an on average lower $P_{\mathrm{r}}$. The impact of varying $d_{\text {ice }}$ will be discussed in more detail below. Using period averages, HdW1999 and JH2000 are more determined by variations in $M$. As a result, both show an increase in $E_{\mathrm{r}}$, corresponding to the increase in $M$, which is larger than found in RACMO2.

\subsubsection{Refreezing of rain}

The amount of refreezing $\left(E_{\mathrm{r}}\right)$ is (partly) determined by the available amount of water including rain $\left(W_{\mathrm{r}}\right)$. However, not all parameterizations take rain falling on cold snow into account in their estimate of $W_{\mathrm{r}}$. Pf1991, Re1991 and Oe1991 assume the contribution of rain to be negligible, because rain constitutes only a small fraction of the total amount of precipitation. In RACMO2, about $6 \%$ of the annual amount of precipitation over the ice sheet falls as rain, with the largest percentages (up to $50 \%$ ) on the southern ice margins. Therefore, refreezing of rain may locally constitute a significant contribution to the total.

Including rain increases the amount of refreezing in all cases (Table 3), by up to $12 \%$. Locally the differences can be much larger. Figure 8 illustrates this for two cases, JH2000 and HdW1999, where JH2000 shows large differences and HdW1999 only small differences. In Oe1991 the difference is smallest, which is due to the fact that in the regions with most rainfall, refreezing is limited by the annual amount of precipitation $\left(P_{\text {tot }}\right)$, not by $W_{\mathrm{r}}$. Note that JH2000 also limits $E_{\mathrm{r}}$ to $P_{\mathrm{tot}}$, but in $\mathrm{JH} 2000$ calculated $E_{\mathrm{r}}$ seldom exceeds $P_{\text {tot }}$ and rain is included in $W_{\mathrm{r}}$. The largest differences are found for the parameterizations that use the annual snowfall as depth of the thermally active layer. In those cases, $W_{\mathrm{r}}$ limits $E_{\mathrm{r}}$ in the lower areas where $C$ is large (such as in the south east), thus increasing $W_{\mathrm{r}}$, which results in more refreezing as can be seen for JH2000 in Fig. 8a. In the case of JH2000 the inclusion of capillary water increases the difference even further, since it provides additional capacity to store water in areas where $C$ is larger than $M$. In the case of HdW1999 the use of a constant $d_{\text {ice }}$ results in the largest differences in 


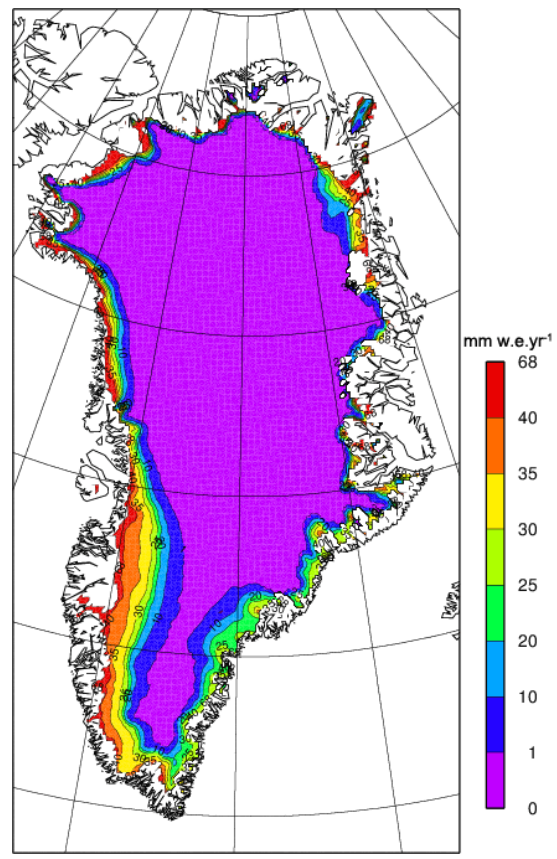

Fig. 12. Difference in refreezing when using different temperature descriptions (Wr2007-HdW1999 with $d_{\text {ice }}=3 \mathrm{~m}$ ), using RACMO2 input fields.

the areas where available liquid water is the limiting factor, which is just above the equilibrium line.

\subsubsection{Depth of the thermally active layer}

All the parameterizations tested in this study, except Oe1991, use an estimate of the depth of the thermally active layer $\left(d_{\text {ice }}\right)$. Oe 1991 implicitly assume $d_{\text {ice }}=2 \mathrm{~m}$ snow by using the average snow temperature of a $2 \mathrm{~m}$ thick layer. The impact of varying $T_{\mathrm{S}}$ will be discussed in more detail below. Parameterizations Pf1991, JH2000 and Re1991 assume that $d_{\text {ice }}$ equals annual snowfall $C$, whereas HdW1999 and Wr2007 assume a constant value for $d_{\text {ice }}$ of $2 \mathrm{~m}$ w.e. and $5 \mathrm{~m}$ w.e., respectively. In the tests we vary $d_{\text {ice }}$, or use $d_{\text {ice }}=C$. Unfortunately, the maximim depth at which refreezing occurs in RACMO2 is not stored and can therefore not be used as a reference or input $d_{\text {ice }}$ field.

The amount of refreezing changes significantly when changing $d_{\text {ice }}$ as can be seen in Table 3 and Fig. 9. Figure 9 shows the difference in $E_{\mathrm{r}}$ when using different values of $d_{\text {ice, }}$ and illustrates that when $d_{\text {ice }}$ increases, refreezing increases, the latter becoming more and more limited by the available amount of liquid water $W_{\mathrm{r}}$. Using a constant $d_{\text {ice }}$, JH2000, HdW1999 and Wr2007, can be tuned to best represent the ice sheet and period averaged RACMO2 refreezing (Table 4). Wr2007 and HdW1999 show the smallest mean difference and the best correspondence in temporal and spatial variability to RACMO2 when $d_{\text {ice }}$ is about $3 \mathrm{~m}$ w.e. (3.07 and $3.45 \mathrm{~m}$ w.e., respectively), while JH2000 shows the best correspondence when $d_{\text {ice }}=1.45 \mathrm{~m}$ w.e.

In all experiments, using $d_{\text {ice }}=C$ drastically reduces the amount of refreezing (Fig. 9b). The reason is that period averaged $C$ is only $0.39 \mathrm{~m}$ w.e. $\mathrm{yr}^{-1}$ in RACMO2. Using $d_{\text {ice }}=C$ results in smaller $P_{\mathrm{r}}$ over those parts of the ice sheet where annual average $C$ is smaller than $3 \mathrm{~m}$ w.e. (Fig. 3a), which is virtually everywhere. In addition, the inter-annual variability almost vanishes, and the spatial correspondence with RACMO2 decreases. JH2000 is the least affected by this choice because they include refreezing of capillary water, which does not depend on the depth of the thermally active layer. Multiplying $C$ with a constant factor increases the amount of refreezing and the temporal variability. Table 4 presents the factors giving best correspondence to RACMO2 for JH2000, HdW1999 and Wr2007. The results are similar to tuning a constant $d_{\text {icee }}$.

\subsubsection{Capillary water}

Pf1991 and JH2000 are the only parameterizations that specifically take into account the refreezing of capillary water at the end of the melt season (second term r.h.s. Eqs. 4 and 5). We tested the impact by removing this term in Eqs. (4) and (5). Note that removing the capillary water in JH2000 equals using HdW1999 with the same $d_{\text {ice }}$ as JH2000. Including capillary water increases the amount of refreezing (Table 3). It also results in a larger temporal variability. However, although RACMO2 also includes the contribution of capillary water, including it in the parameterizations does not result in a better spatial agreement with RACMO2.

Figure 10 shows that capillary water is a significant contributor to refreezing in areas were melt $M$ does not exceed the amount of snowfall $C$. This is especially the case in Pf1991 where, due to the mask formulation and the use of $T_{\mathrm{f}}=-15^{\circ} \mathrm{C}$, the remaining cold content is very small, resulting in only a small area where refreezing occurs. In $\mathrm{JH} 2000$, the areas where the difference is zero are those where $M$ exceeds $C$ and those where $P_{\mathrm{r}}$ minus the possible capillary contribution is larger than $M$. In case $d_{\text {ice }}$ is constant, the latter area is larger because $P_{\mathrm{r}}$ remains larger compared to the case where $d_{\text {ice }}=C$, since over large areas of the ice sheet $C$ is on average smaller than $2 \mathrm{~m}$ w.e. (see Fig. 3a).

\subsubsection{Density}

When including the capillary water content, the additional amount of refreezing that may occur depends on the chosen densities. JH2000 (Eq. 5) use a pore close-off density $\rho_{\mathrm{pc}}=960 \mathrm{~kg} \mathrm{~m}^{-3}$, which they define as the density of water saturated snow, while Pf1991 (Eq. 4) use a value of $900 \mathrm{~kg} \mathrm{~m}^{-3}$. They both use a firn density $\rho_{\mathrm{f}}=300 \mathrm{~kg} \mathrm{~m}^{-3}$. Changing $\rho_{\mathrm{pc}}$ or $\rho_{\mathrm{f}}$ changes the factor determining how much water can be retained. $\rho_{\mathrm{pc}}$ is varied between $830 \mathrm{~kg} \mathrm{~m}^{-3}$, the 


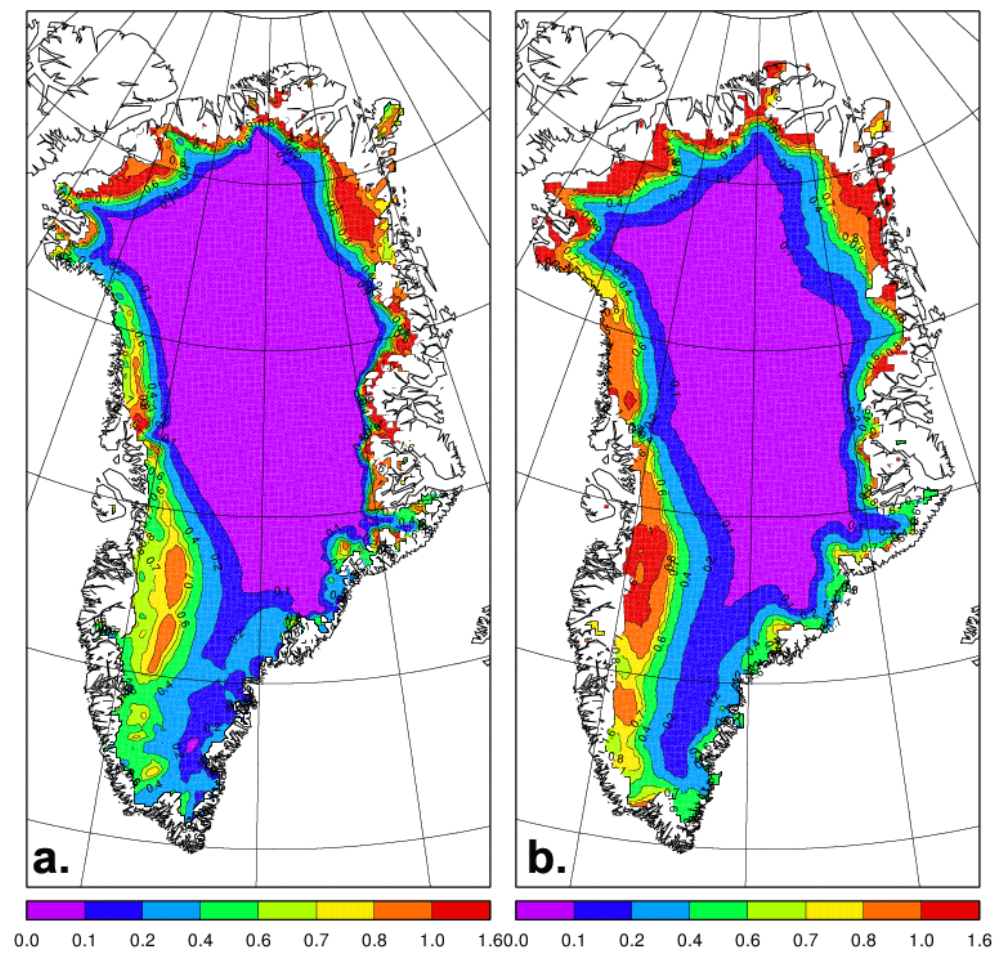

Fig. 13. Fraction of refreezing over snowfall $\left(E_{\mathrm{r}} / C\right)$ from RACMO2 (a) and MAR (b) fields.

actual pore close of density, and $960 \mathrm{~kg} \mathrm{~m}^{-3}$. Tests with the density factor are presented in Table 3 and Fig. 11.

Increasing the density factor, either by increasing $\rho_{\mathrm{pc}}$ or decreasing $\rho_{\mathrm{f}}$, results in a larger amount of refreezing. The increase is largest in areas around the equilibrium line. Increasing the density factor further results in a larger inter-annual variability and less spatial correspondence with RACMO2 in case of JH2000 and more in case of Pf1991 (Table 3). Changing $\rho_{\mathrm{f}}$ has the largest impact, but the change has to be considerable to have a significant effect. This is because changing density only has effect in areas were less than the annual amount of snowfall $C$ melts away, and where $P_{\mathrm{r}}$ is the limiting factor, not $W_{\mathrm{r}}$.

Reeh et al. (2005) present $\rho_{\mathrm{f}}$ as a function of $T_{\mathrm{S}}$ based on observations on the GrIS. Using this function in JH2000, the effect is similar to using a higher constant value of $\rho_{\mathrm{f}}$, i.e. a reduction in amount of refreezing and an increase in spatial correspondence to RACMO2 (Fig. 11c, Table 3). Using RACMO2 output, $\rho_{\mathrm{f}}$ as a function of altitude, snowfall or temperature can be derived. However, the skill of the resulting functions is limited, the scatter large and largest in lower elevation areas with higher temperatures and higher snow fall amounts. These are the areas where the differences between RACMO2 refreezing and the parameterizations is largest (Fig. 7). This explains why including such functions does not improve the correspondence between RACMO2 and JH2000.

\subsubsection{Temperature}

In several parameterizations temperature is used as a measure for the cold content of the snow. Except for Pf1991, all parameterizations were forced by RACMO2 surface temperatures $T_{\mathrm{S}}$. Pf1991 uses a representative value of the firn temperature at the firn limit $\left(-15^{\circ} \mathrm{C}\right)$. The impact of the parameterized refreezing to variations the temperature indicates in fact how well this temperature represents the cold content of the snow.

Table 3 shows that Pf1991 and JH2000 are not very sensitive to reasonable changes in $T_{\mathrm{s}}$ while HdW1991, Wr2007 and Oe1991 are more sensitive. In Oe1991 changes in $E_{r}$ due to changes in $T_{\mathrm{S}}$ are strongly non-linear due to the exponential relation between $T_{\mathrm{s}}$ and $P_{\mathrm{r}}$. In case of equal $d_{\mathrm{ice}}$, the temperature description is responsible for the main difference between HdW1999 and Wr2007 (Fig. 12). Figure 5 illustrates the temperature used by both parameterizations. Due to the combined use of annual averaged and winter temperature, the temperature factor used by $\mathrm{Wr} 2007$ is more variable in time than the annual mean temperature used in HdW1999. This does not result in a larger sensitivity to changes in temperature in $\mathrm{Wr} 2007$. 


\subsection{7 $P_{\max }$}

Compared to RACMO2, $P_{\mathrm{r}}=0.6 C$ represents the amount and temporal variability in refreezing well in areas where $P_{\mathrm{r}}$ is the limiting factor (Table 2). Tuning results in an even better correspondence in average amount, although the resulting value of $P_{\max }$ does not deviate much from $0.6(0.65$, Table 4). When including Rain, a slightly lower value results in the best correspondence $\left(P_{\max }=0.56\right)$. In both cases (with or without rain), increasing $P_{\max }$ increases the amount of refreezing below the elevation where $W_{\mathrm{r}}$ is the limiting factor and increases the area where $W_{\mathrm{r}}$ is the limiting factor. It also increases the temporal variability and decreases the spatial correspondence with RACMO2. Decreasing $P_{\max }$ results in the opposite: it decreases the temporal variability and increases the correspondence with RACMO2.

From RACMO2 (and MAR) fields of $C$ and $E_{\mathrm{r}}$, the fraction of $C$ that is refrozen can be calculated (Fig. 13). Interesting feature in this figure is the northern marginal areas where the fraction is larger than 1 and thus more than the annual amount of snowfall refreezes. This is the result of multiple cycles of melt and refreezing of the same snow/ice. This happens over the whole GrIS, but in areas where little or no runoff takes place, and $C$ is small, this can result in $E_{\mathrm{r}} / C>1$. Since the cold snow pack warms up due the energy provided by refreezing, the increase in melt over the period 1958-2008 (Fig. 2) will degrade the refreezing capacity in these areas to the point that runoff starts. In contrast, in the southeastern marginal zone $E_{\mathrm{r}}$ is small compared to $C$. Only on the western margin of the ice sheet are there significant areas where the fraction is about 0.6 , similar to the value of $P_{\max }$ measured by Braithwaite et al. (1994) in this area. The ice sheet average value of $E_{\mathrm{r}} / C$ is 0.28 (MAR 0.34 ); this high value is the result of the multiple cycles of melt and refreezing. The higher value in MAR is due to the on average larger amount of $E_{\mathrm{r}}$ and lower amount of $C$. Whether the modeled $E_{r} / C$ is reasonable is difficult to determine given the lack of observations for validation.

\section{Summary and conclusions}

In this study we applied several parameterizations that calculate the annual amount of refreezing to the Greenland ice sheet. In the absence of refreezing observations we compare the results to output of the RACMO2 and MAR regional climate models, that both include an explicit scheme to calculate retention and refreezing as a function of snow depth, temperature and density. The parameterizations are forced with output from the same models for consistency. Almost all refreezing parameterizations discussed here use temperature and an estimate of the depth of the thermally active layer to determine the cold content of the snow. In RACMO2 and MAR, water may percolate to any depth depending on the vertical temperature and density distribution in the snow/firn.
Note that none of the parameterizations, or the regional climate models, explicitly include heterogeneous infiltration (piping) of water, a process known to be important for heating cold firn (Marsh and Woo, 1984; Pfeffer and Humphrey, 1996).

In the absence of observations we use RACMO2 as reference. Refreezing in RACMO2 and MAR agree well; annual, period average (1958-2008) and ice sheet averaged values differ by $\sim 4.5 \%$, temporal variability is similar $\left(\mathrm{Std} 1=19.8 \mathrm{~mm}\right.$ w.e $\mathrm{yr}^{-1}$ and $16.6 \mathrm{mmw}^{-e} \mathrm{yr}^{-1}$, respectively) and spatial correspondence reasonably good ( $\operatorname{Std} 2=$ $40.9 \mathrm{~mm}$ w.e. $\mathrm{yr}^{-1}$, Table 2). Differences are explained by the chosen amount of irreducible water content $(6 \%$ MAR and $2 \%$ RACMO2), the albedo formulation, the minimum thickness of the uppermost snow layer $(<1 \mathrm{~cm}$ MAR and $\sim 6.5 \mathrm{~cm}$ RACMO2), and differences in atmospheric temperature and precipitation. All in all, correspondence between both models is better than with any of the parameterizations. This provides confidence in the RCMs since differences between MAR and RACMO2 are only partly the result of the snow model formulation and partly due to the atmospheric forcing (mainly temperature and precipitation). In contrast, differences between the parameterizations and RACMO2/MAR are solely due to the refreezing formulation.

The annual, period average (1958-2008) and ice sheet averaged amount of refreezing calculated with the different parameterizations differs up to a factor 2 with RACMO2 and MAR (Table 2). The spatial fields show large differences as well, especially in the lower areas of the ice sheet (up to a factor 5). Janssens and Huybrechts (2000) also noted large differences in parameterized refreezing in these areas, which they related to the chosen depth of the thermally active layer. Our results confirm this large sensitivity as well as the large impact this has on refreezing in the marginal areas. Depending on parameterization, using period or annual average input fields, changing input temperature or density has a large impact on the results as well. All parameterizations can be tuned within realistic limits, to produce ice sheet and annual average amount of refreezing similar to RACMO2, but this does not necessarily result in better spatial correspondence (Table 4). After tuning, the temporal variability of Wr2007 and the spatial variability of HdW1999 are most similar to RACMO2.

Care must be taken when choosing a parameterization, because they were developed for different applications. For example, Pf1991 was not intended to be applied to the full ice sheet, but was developed to describe the effect of refreezing on the average GrIS mass balance profile. The lack of refreezing below the runoff line in this method is therefore, of limited importance, since in this area the refrozen mass melts again later in the season to run off. Note that the elevation of the chosen runoff line should be close to the equilibrium line. The $P_{\max }$ formulation works well on annual ice sheet averages, because $P_{\max }$ corresponds to the fraction of $C$ that is refrozen in the area where most refreezing occurs. The 
amount of refreezing in Oe1991 depends on available energy and an average temperature over a $2 \mathrm{~m}$ snow layer. Oe1991 is very sensitive to changes in this temperature. However, Oe1991 was designed for application in an energy balance model that includes a simple snow model, in which the snow temperature changes when refreezing occurs. To obtain reasonable results in our test, the refreezing is limited to the total annual precipitation $P_{\text {tot }}$. It is questionable whether Oe1991 will work similarly well in other settings and without those constraints.

The presented parameterizations and both models (RACMO2 and MAR) are based on the same principles and are on average in reasonable agreement. RACMO2 and MAR surface mass balance fields show good agreement with surface and satellite observations (Ettema et al., 2009; Van den Broeke et al., 2009; Fettweis et al., 2011). Furthermore, Greuell and Konzelman (1994); Lefebre et al. (2003); Reijmer and Hock (2008) show for single locations that SOMARS and Crocus are capable of realistically modeling the observed snow temperature, density and water content. In combination with the spatial correspondence between RACMO2 and MAR, this implicitly gives confidence in modeled refreezing. The lack of spatial correspondence between the different parameterizations and the models indicates that, at least in the parameterizations but likely in the models as well, not all processes are included or described adequately. For example, omitting piping may be important in the snow models in RACMO2 and MAR because it affects the depth at which refreezing occurs, thus affecting the vertical temperature and density distribution (Humphrey et al., 2012). It also indicates that it is unlikely that tuning the parameterizations to e.g. an observation results in a correct spatial distribution, or that the results are transferable to other locations and/or periods. A next step in the study of refreezing would be validation of available comprehensive snow models against observations; including the process of piping in these models; and using them in models such as RACMO2 and MAR to study the impact of refreezing on the GrIS surface mass balance.

Acknowledgements. We thank R. Fausto, T. Pfeffer, I. Janssens and an anonymous referee for their constructive comments. This work is funded by the Utrecht University and the Netherlands Polar Programme. The ECMWF and KNMI are thanked for providing computing and data archiving support.

Edited by: J. L. Bamber

\section{References}

Bøggild, C.: Simulation and parameterization of superimposed ice formation, Hydrol. Process., 21, 1561-1566, 2007.

Bougamont, M., Bamber, J. L., and Greuell, W.: A surface mass balance model for the Greenland ice sheet, J. Geophys. Res., 110, doi:10.1029/2005JF000348, 2005.

Box, J., Bromwich, D., Veenhuis, B., Bai, L.-S., Stroeve, J., Rogers, J., Steffen, K., Haran, T., and Wang, S.-H.: Greenland Ice Sheet Surface Mass Balance Variability (1988-2004) from Calibrated Polar MM5 Output, J. Climate, 19, 2783-2800, 2006.

Braithwaite, R., Laternser, M., and Pfeffer, W.: Variations of nearsurface firn density in the lower accumulation area of the Greenland ice sheet, Pakitsoq, West Greenland, J. Glaciol., 40, 477485, 1994.

Brun, E., Martin, E., V. Simon, C. G., and Coleou, C.: An energy and mass model of snow cover suitable for operational avalanche forecasting, J. Glaciol., 35, 333-342, 1989.

Brun, E., David, P., Sudul, M., and Brunot, G.: A numerical model to simulate snow-cover stratigraphy for operational avalanche forecasting, J. Glaciol., 38, 13-22, 1992.

Coléou, C. and Lesaffre, B.: Irreducible water saturation in snow: Experimental results in a cold laboratory, Ann. Glaciol., 26, 6468, 1998.

Ettema, J., van den Broeke, M., van Meijgaard, E., van de Berg, W., Bamber, J., Box, J., and Bales, R.: Higher surface mass balance of the Greenland ice sheet revealed by high-resolution climate modeling, Geophys. Res. Lett., 36, doi:10.1029/2009GL038110, 2009.

Ettema, J., van den Broeke, M., van Meijgaard, E., and van de Berg, W.: Climate of the Greenland ice sheet using a high-resolution climate model - Part 2: Near-surface climate and energy balance, The Cryosphere, 4, 529-544, 2010a.

Ettema, J., van den Broeke, M., van Meijgaard, E., van de Berg, W., Box, J., and Steffen, K.: Climate of the Greenland ice sheet using a high-resolution climate model - Part 1: Evaluation, The Cryosphere, 4, 511-527, 2010b.

Fausto, R., Ahlstrøm, A., van As, D., Johnsen, S., Langen, P., and Steffen, K.: Improving surface boundary conditions with focus on coupling snow densification and meltwater retention in largescale ice-sheet models of Greenland, J. Glaciol., 55, 869-878, 2009.

Fettweis, X.: Reconstruction of the 1979-2006 Greenland ice sheet surface mass balance using the regional climate model MAR, The Cryosphere, 1, 21-40, 2007, http://www.the-cryosphere-discuss.net/1/21/2007/.

Fettweis, X., Gallée, H., Lefebre, F., and van Ypersele, J.: Greenland surface mass balance simulated by a regional climate model and comparison with satellite-derived data in 1990-1991, Climate Dynamics, 24, 623-640, doi:10.1007/s00382-005-0010-y, 2005.

Fettweis, X., Tedesco, M., van den Broeke, M., and Ettema, J.: Melting trends over the Greenland ice sheet (1958-2009) from spaceborne microwave data and regional climate models, The Cryosphere, 5, 359-375, 2011, http://www.the-cryosphere-discuss.net/5/359/2011/.

Gallée, H. and Duynkerke, P.: Air-snow interactions and the surface energy and mass balance over the melting zone of west Greenland during the Greenland Ice Margin Experiment, J. Geophys. Res., 102, 13 813-13 824, 1997. 
Gallée, H. and Schayes, G.: Development of a Three-Dimensional Meso- $\gamma$ primitive equation model: katabatic winds simulation in the area of Terra Nova Bay, Antarctica, Mon. Weather Rev., 122, $671-685,1994$

Gallée, H., Guyomarch, G., and Brun, E.: Impact of Snow Drift on the Antarctic Ice Sheet Surface Mass Balance: Possible Sensitivity to Snow-Surface Properties, Boundary-Layer Meteorol., 99, $1-19,2001$.

Greuell, W. and Konzelman, T.: Numerical modelling of the energy balance and the englacial temperature of the Greenland ice sheet. Calculations for the ETH-Camp location (West Greenland, $1155 \mathrm{~m}$ a.s.1.), Global and Planetary Change, 9, 91-114, doi:10.1016/0921-8181(94)90010-8, 1994.

Hanna, E., Huybrechts, P., Steffen, K., Cappelen, J., Huff, R., Shuman, C., Irvine-Fynn, T., Wise, S., and Griffiths, M.: Increased Runoff from Melt from the Greenland Ice Sheet: A Response to Global Warming, J. Climate, 21, 331-341, 2008.

Herron, M. and Langway, C.: Firn densification: An empirical model, J. Glaciol., 25, 373-385, 1980.

Humphrey, N., Harper, J., and Pfeffer, W.: Thermal tracking of meltwater retention in Greenland's accumulation area, J. Geophys. Res., 117, doi: 10.1029/2011JF002083, 2012.

Huybrechts, P. and de Wolde, J.: The Dynamic Response of the Greenland and Antarctic ice sheets to Multiple-century climate warming, J. Climate, 12, 2169-2188, 1999.

Janssens, I. and Huybrechts, P.: The treatment of meltwater retention in mass-balance parameterizations of the Greenland ice sheet, Ann. Glaciol., 31, 133-140, 2000.

Lefebre, F., Gallée, H., van Ypersele, J. P., and Greuell, W.: Modeling of snow and ice melt at ETH-Camp (West Greenland): A study of surface albedo, J. Geophys. Res., 108, 4231, doi:10.1029/2001JD001160, 2003.

Lefebre, F., Fettweis, X., Gallée, H., van Ypersele, J., Marbaix, P., Greuell, W., and Calanca, P.: Evaluation of a high-resolution regional climate simulation over Greenland, Climate Dynamics, 25, 99-116, 2005.

Lenaerts, J., van den Broeke, M., Déry, S., van Meijgaard, E., van de Berg, W., Palm, S., and Rodrigo, J. S.: Modeling drifting snow in Antarctica with a regional climate model, part I: Methods and model evaluation, J. Geophys. Res., 117, doi:10.1029/2011JD016145, 2012.

Marsh, P. and Woo, M.: Wetting front and refreezing of meltwater within a snow cover. 1. Observation in the Canadian Arctic, Water Resour. Res., 20, 1853-1864, 1984.

Oerlemans, J.: The mass balance of the Greenland ice sheet: sensitivity to climate change as revealed by energy balance modelling, The Holocene, 1, 40-49, 1991.

Paterson, W.: The Physics of Glaciers, Pergamon, 480 pp, 1994.

Pfeffer, W. and Humphrey, N.: Determination of timing and location of water movement and ice-layer formation by temperature measurements in sub-freezing snow, J. Glaciol., 42, 292-304, 1996.
Pfeffer, W., Illangasekare, T., and Meier, M.: Analysis and modelling of melt-water refreezing in dry snow, J. Glaciol., 36, 238 246, 1990.

Pfeffer, W., Meier, M., and Illangasekare, T.: Retention of Greenland runoff by refreezing: implications for projected future sea level change, J. Geophys. Res., 96, 22117-22124, 1991.

Reeh, N.: Parameterization of melt rate and surface temperature on the greenland ice sheet, Polarforschung, 59, 113-128, 1991.

Reeh, N., Fisher, D., Koerner, R., and Clausen, H.: An empirical firn-densification model comprising ice lenses, Ann. Glaciol., 42, 101-106, 2005.

Reijmer, C. and Hock, R.: Internal accumulation on Storglaciären, Sweden, in a multi-layer snow model coupled to a distributed energy- and mass-balance model, J. Glaciol., 54, 61-72, 2008.

Rignot, E., Velicogna, I., van den Broeke, M., Monaghan, A., and Lenaerts, J.: Acceleration of the contribution of the Greenland and Antarctic ice sheets to sea level rise, Geophys. Res. Lett., 38, doi:10.1029/2011GL046583, 2011.

Schneider, T. and Jansson, P.: Internal accumulation in firn and its significance for the mass balance of Storglaciären, Sweden, J. Glaciol., 50, 25-34, 2004.

Trabant, D. and Mayo, L.: Estimation and effects of internal accumulation on five glaciers in Alaska, Ann. Glaciol., 6, 113-117, 1985.

Van de Berg, W., van den Broeke, M., Reijmer, C., and van Meijgaard, E.: Reassessment of the Antarctic surface mass balance using calibrated output of a regional atmospheric climate model, J. Geophys. Res., 111, doi:10.1029/2005JD006495, 2006.

Van den Broeke, M., Bamber, J., Ettema, J., Rignot, E., Schrama, E., van de Berg, W., van Meijgaard, E., Velicogna, I., and Wouters, B.: Partitioning recent Greenland mass loss, Science, 326, 984 986, 2009.

Van Dusen, M.: International Critical Tables of Numerical Data: Physics, Chemistry and Technology, chap. Thermal conductivity of non-metallic solids, 216-217, McGraw Hill, 1929.

Van Meijgaard, E., van Ulft, L., van de Berg, W., Bosveld, F., van den Hurk, B., Lenderink, G., and Siebesma, A.: The KNMI regional atmospheric climate model, version 2.1, KNMI Tech. Rep. 302, Royal Dutch Meteorological Institute (KNMI), De Bilts, the Netherlands, 2008.

Wright, A., Wadham, J., Siegert, M., Luckman, A., Kohler, J., and Nuttall, A.: Modeling the refreezing of meltwater as superimosed ice on a high Arctic glacier: A comparison of approaches, J. Geophys. Res., 112, 2007.

Yen, Y.-C.: Review of thermal properties of snow, ice and sea ice, Rep. 81-10, CRREL, Cold Reg. Res. and Eng. Lab., Hanover, N.H., 1981.

Zuo, Z. and Oerlemans, J.: Modelling albedo and specific balance of the Greenland ice sheet: Calculations for the Søndre Strømfjord transect, J. Glaciol., 42, 305-317, 1996. 